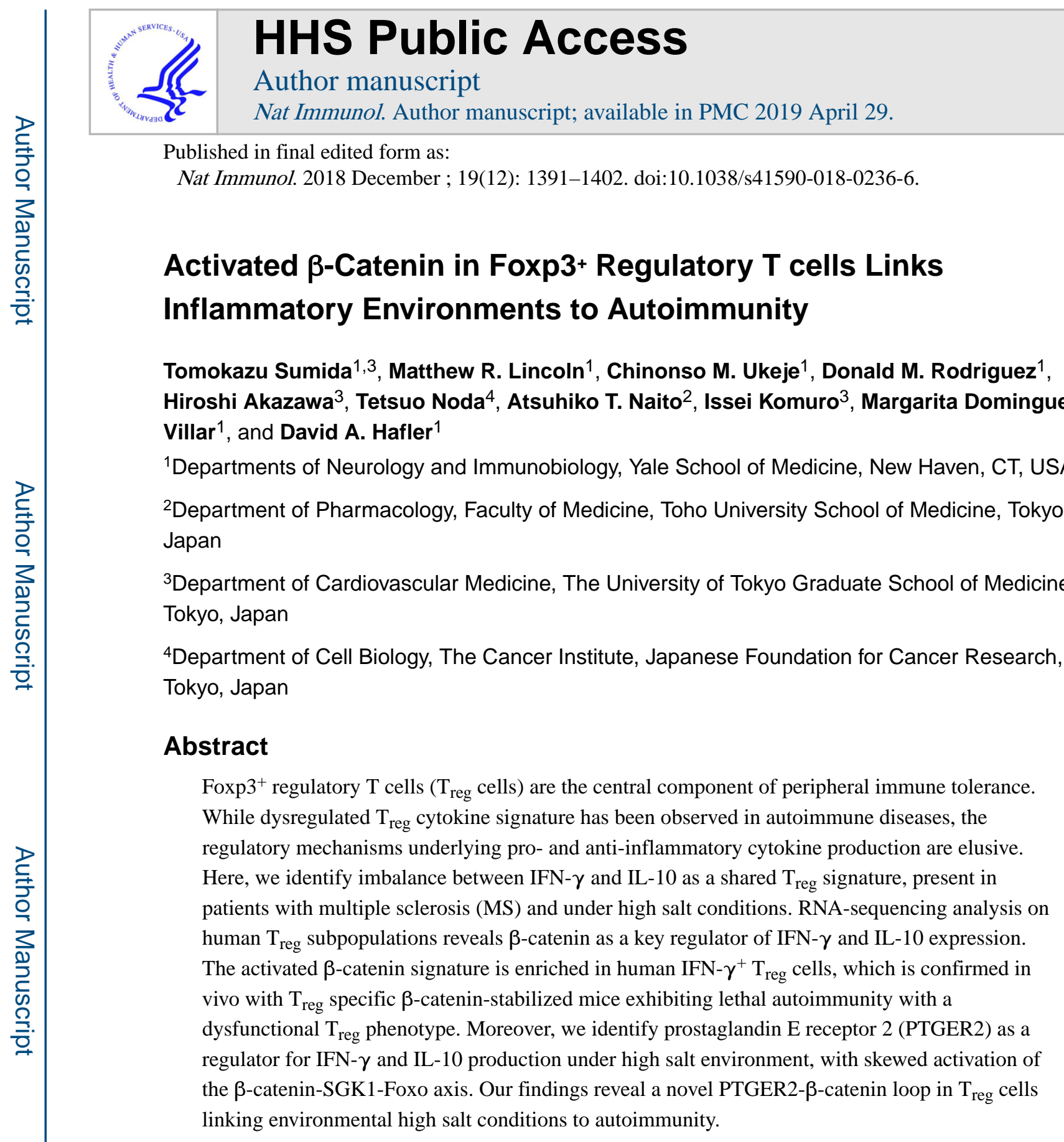

Published in final edited form as:

Nat Immunol. 2018 December ; 19(12): 1391-1402. doi:10.1038/s41590-018-0236-6.

\title{
Activated $\beta$-Catenin in Foxp3+ Regulatory T cells Links Inflammatory Environments to Autoimmunity
}

\author{
Ukeje ${ }^{1}$, Donald M. Rodriguez ${ }^{1}$, \\ Hiroshi Akazawa ${ }^{3}$, Tetsuo Noda ${ }^{4}$, Atsuhiko T. Naito ${ }^{2}$, Issei Komuro ${ }^{3}$, Margarita Dominguez- \\ Villar $^{1}$, and David A. Hafler ${ }^{1}$ \\ ${ }^{1}$ Departments of Neurology and Immunobiology, Yale School of Medicine, New Haven, CT, USA \\ 2Department of Pharmacology, Faculty of Medicine, Toho University School of Medicine, Tokyo,
}

ef Department of Cell Biology, The Cancer Institute, Japanese Foundation for Cancer Research, Tokyo, Japan

\section{Abstract}

Foxp $3^{+}$regulatory $\mathrm{T}$ cells $\left(\mathrm{T}_{\text {reg }}\right.$ cells) are the central component of peripheral immune tolerance While dysregulated $\mathrm{T}_{\text {reg }}$ cytokine signature has been observed in autoimmune diseases, the regulatory mechanisms underlying pro- and anti-inflammatory cytokine production are elusive. Here, we identify imbalance between IFN- $\gamma$ and IL-10 as a shared $\mathrm{T}_{\text {reg }}$ signature, present in patients with multiple sclerosis (MS) and under high salt conditions. RNA-sequencing analysis on man $T_{\text {reg }}$ subpopulations reveals $\beta$-catenin as a key regulator of IFN- $\gamma$ and IL-10 expression. The activated $\beta$-catenin signature is enriched in human IFN- $\gamma^{+} \mathrm{T}_{\text {reg }}$ cells, which is confirmed in vivo with $T_{\text {reg }}$ specific $\beta$-catenin-stabilized mice exhibiting lethal autoimmunity with a dysfunctional $\mathrm{T}_{\text {reg }}$ phenotype. Moreover, we identify prostaglandin $\mathrm{E}$ receptor 2 (PTGER2) as a linking environmental high salt conditions to autoimmunity.

\footnotetext{
Users may view, print, copy, and download text and data-mine the content in such documents, for the purposes of academic research, subject always to the full Conditions of use:http://www.nature.com/authors/editorial_policies/license.html\#terms

Correspondence should be addressed to T.S. (tomokazu.sumida@yale.edu).

*Present Address; Donald M. Rodriguez, University of Chicago, Chicago, IL, USA

Contributions

T.S., D.M.R., and C.M.U. performed in vitro experiments with the help of M.R.L. and M.D.V.; T.S. and A.T.N. performed in vivo experiments with the help of H.A. and T.N.; T.S. and M.R.L. analyzed the RNA-seq data under the supervision of D.A.H.; T.S performed data analysis and wrote the manuscript under the supervision of A.T.N., I.K., M.R.L., M.D.V., and D.A.H.; A.T.N, I.K., M.D.V. and D.A.H. supervised the overall study.

Competing interests

The authors declare no competing interests.

Data availability

RNA-seq data are available in the GEO repository with accession code GSE116283. The remaining data that support the findings of this study are available from the corresponding authors upon request.
} 


\section{Reporting Summary}

Further information on experimental design is available in the Nature Research Reporting Summary linked to this article.

\section{Introduction}

The homeostatic maintenance of $\mathrm{T}$ cells is finely tuned by $\mathrm{T}_{\text {reg }}$ cells. $\mathrm{T}_{\text {reg }}$ cells play a distinct role from the other $\mathrm{CD} 4^{+} \mathrm{T}$ cells in dampening prolonged inflammation and preventing aberrant autoimmunity ${ }^{1}$. Although $\mathrm{T}_{\text {reg }}$ cells are potent suppressors of immune function, the number of $\mathrm{T}_{\text {reg }}$ cells is often normal in a variety of autoimmune diseases, including multiple sclerosis (MS) ${ }^{2,3}$. These observations suggest that not only a quantitative, but also a functional dysregulation of $\mathrm{T}_{\text {reg }}$ cells contributes to the development of autoimmunity.

$\mathrm{T}_{\text {reg }}$ cells display their suppressive capacity through both contact-dependent and cytokinemediated mechanisms ${ }^{4}$. $\mathrm{T}_{\text {reg }}$ cells demonstrate substantial heterogeneity and the balance between pro- and anti-inflammatory populations is finely regulated to maintain immunologic homeostasis ${ }^{4}$. IFN- $\gamma$ marks dysfunctional $\mathrm{T}_{\text {reg }}$ cells in patients with autoimmunity (MS ${ }^{5}$ and $\mathrm{T}^{1} \mathrm{D}^{6}$ ) and cancer (glioblastoma ${ }^{7}$ ). Additionally, $\mathrm{T}_{\text {reg }}$ cells producing the anti-inflammatory cytokine IL-10 play prominent roles in suppressing the immune response at environmental interfaces and development of mature memory $\mathrm{CD} 8^{+} \mathrm{T}$ cells to prevent autoimmunity and chronic infection in mice ${ }^{8,9}$. These studies suggest that the balance between IFN- $\gamma$ and IL-10 production in $\mathrm{T}_{\text {reg }}$ cells is central in the maintenance of immune homeostasis; however, the molecular mechanisms underlying this regulatory balance are not known.

Human autoimmune disease results from an interplay between genetic factors and environmental triggers. In this regard, MS is an autoimmune disease that results from the complex interaction of predominantly common genetic variants and environmental factors ${ }^{10}$, with 233 common risk haplotypes identified to date ${ }^{11,12}$. Several environmental factors are associated with an increased risk of MS including vitamin D insufficiency, smoking, obesity, and a high salt diet (HSD $)^{13}$. Previous studies showed that a HSD exacerbated neuroinflammation in the experimental autoimmune encephalomyelitis (EAE) model of MS, and that higher salt concentration within the physiological range skewed naive $\mathrm{CD} 4^{+} \mathrm{T}$ cells into pro-inflammatory $\mathrm{T}_{\mathrm{H}} 17$ cells and impaired $\mathrm{T}_{\text {reg }}$ suppressive function through induction of IFN- $\gamma$ expression ${ }^{14,15,16}$. Studies using murine models of autoimmune disease are accumulating to support this theory ${ }^{17,18}$ and recent magnetic resonance imaging studies revealed higher sodium intensity in acute MS lesions compared to chronic lesions, suggesting more sodium accumulation within the pathogenic microenvironment in MS brain ${ }^{19}$. However, it remains unknown whether a high salt diet has a direct impact on MS clinical activity ${ }^{20}$.

$\beta$-catenin is an essential component of the canonical Wnt signaling pathway and involved in a variety of biological processes including carcinogenesis, stem cell maintenance, organogenesis, and aging 21,22 . Although $\beta$-catenin and canonical Wnt signaling have been studied in immune system, the specific mechanisms by which $\beta$-catenin affects $T_{\text {reg }}$ function 
and their role in modulating cytokine production by $\mathrm{T}_{\text {reg }}$ cells, in particular in the context of human autoimmune disease, is poorly understood.

Here, we show that the imbalance between IFN- $\gamma$ and IL-10 is a shared $\mathrm{T}_{\text {reg }}$ signature observed in the patients with MS and high salt environment. By performing unbiased RNAseq analysis on human $\mathrm{T}_{\text {reg }}$ subpopulations, we identify $\beta$-catenin as central in maintaining $\mathrm{T}_{\text {reg }}$ function and regulating both IFN- $\gamma$ and IL-10 cytokine production. Moreover, we clarify a role for $\beta$-catenin in mediating the high salt-induced pro-inflammatory signature by creating a feed forward loop with PTGER2, which is uniquely upregulated under high salt conditions. Our findings suggest that the $\beta$-catenin-PTGER2 axis serves as a bridge between environmental factors and autoimmune disease by modulating $\mathrm{T}_{\text {reg }}$ function and this axis may be involved in the pathogenesis of autoimmune disease.

\section{Results}

\section{$T_{\text {reg }}$ cytokine imbalance in multiple sclerosis and high salt environment}

Previous studies have identified a pro-inflammatory $\mathrm{T}_{\text {reg }}$ population characterized by the secretion of IFN- $\gamma$. This population is dysfunctional both in vitro and in vivo, and a high frequency of this population is associated with autoimmune disease ${ }^{5,6,7}$. However, the balance between pro- and anti-inflammatory $\mathrm{T}_{\text {reg }}$ populations has not been defined. To address this question, we evaluated the production of pro-inflammatory (IFN- $\gamma$ ) and antiinflammatory (IL-10) cytokines by circulating human $\mathrm{T}_{\text {reg }}$ cells from healthy subjects and patients with MS by flow cytometry. Based on our observation that CD25hiCD127lonegCD45RO ${ }^{+} \mathrm{T}_{\text {reg }}$ cells (memory $\mathrm{T}_{\text {reg }}$ cells; $\mathrm{mT}_{\text {reg }}$ cells) are the major source for effector cytokine expression in human $\mathrm{T}_{\text {reg }}$ cells (Supplementary Fig. 1), we focused on $\mathrm{mT}_{\text {reg }}$ cells, so as to avoid the potential bias caused by the variable ratio of naive $\mathrm{T}_{\text {reg }}$ cells and $\mathrm{mT}_{\text {reg }}$ cells between subjects. We found that $\mathrm{mT}_{\text {reg }}$ cells isolated from MS patients (MS- $\mathrm{T}_{\text {reg }}$ ) produced more IFN- $\gamma$ and less IL-10 compared to healthy donors, and the ratio of IFN- $\gamma$ to IL-10 producing $\mathrm{T}_{\text {reg }}$ cells further highlights this imbalance (Fig. 1a, b). Furthermore, we examined the mRNA expression of $I F N G$ and $I L 10$ genes in $\mathrm{mT}_{\text {reg }}$ cells without PMA plus iomomycin stimulation, better reflecting the situation in vivo, and identified a trend similar to that seen in protein expression (Fig. 1c).

We recently demonstrated that $\mathrm{T}_{\text {reg }}$ cells exposed to high salt concentrations exhibited a dysfunctional phenotype with a pro-inflammatory cytokine signature skewed towards IFN$\gamma^{16}$. We sought to determine whether high salt could also impair the IFN- $\gamma$ :IL-10 balance and found that the high salt environment caused an increase in IFN- $\gamma$ and decrease in IL-10 production in human $\mathrm{mT}_{\text {reg }}$ cells after $96 \mathrm{~h}$ in culture (Fig. 1d, e). Gene expression kinetics of $I F N G$ and $I L 10$ by using qPCR identified early $(8 \mathrm{~h})$ and late $(96 \mathrm{~h})$ waves of gene expression. High salt stimulation suppressed the early wave of IFNG and IL10, and enhanced the late wave of $I F N G$ but not $I L I O$ (Fig. 1f). These findings suggest that the imbalance of IFN- $\gamma$ :IL-10 induced by continuous exposure to high salt conditions, which is not observed at the phase of acute response to high salt stress, might capture the dysfunctional $\mathrm{T}_{\text {reg }}$ properties in the setting of autoimmunity. 


\section{$\beta$-catenin regulates relative production of IFN- $\gamma$ and IL-10 in human $\mathrm{T}_{\text {reg }}$ cells}

The molecular mechanisms underpinning the balance between IFN- $\gamma$ and IL-10 in $\mathrm{T}_{\text {reg }}$ cells were largely unknown. To address this question, we performed RNA-sequencing (RNAseq)-based genome-wide transcriptome analysis on human $\mathrm{T}_{\text {reg }}$ subsets defined by IFN- $\gamma$ and IL-10 production. $\mathrm{mT}_{\text {reg }}$ cells isolated from peripheral mononuclear cells of healthy subjects were stimulated with PMA plus iomomycin for $4 \mathrm{~h}$ ex vivo. After applying cytokine capture kits for IFN- $\gamma$ and IL-10, we sorted four different subpopulations (IFN- $\gamma$ single positive (IFN- $\gamma$ SP), IL-10 single positive (IL10SP), IFN- $\gamma$ and IL-10 double positive (DP), and double negative (DN)), and we performed RNA-seq on each subpopulation (Fig 2a). We identified 672 differentially expressed genes between IFN- $\gamma$ SP and IL10SP and the four populations could be distinguished by their gene expression profiles (Fig. 2b). Of note, the IFN- $\boldsymbol{\gamma}$-producing populations were highly distinct from IFN- $\boldsymbol{\gamma}$-negative populations, suggesting that IFN- $\boldsymbol{\gamma}$-secreting $\mathrm{T}_{\text {reg }}$ cells represent a more dominant signature than IL-10secreting $\mathrm{T}_{\text {reg }}$ cells. We also identified ten clusters of co-expressed genes (C1-C10) across the populations. IFN- $\gamma$ and IL-10-associated genes are enriched in $\mathrm{C} 9$ and $\mathrm{C} 10$ (e.g. CXCR3, CD226, and NKG7) and $\mathrm{C} 1$ and $\mathrm{C} 2$ (e.g. MAF, SOCS3, and NOTCH2), respectively.

To predict the key transcriptional regulators that account for IFN- $\gamma$ and IL-10 production, we performed an upstream regulator analysis in Ingenuity Pathway Analysis (IPA), using differentially expressed genes from each population (Supplementary Table 1). We identified $\beta$-catenin $(C T N N B 1)$ as one of the top upstream regulators in the $\mathrm{T}_{\text {reg }}$ populations producing IFN- $\gamma$ and/or IL-10 compared to DN. Intriguingly, $\beta$-catenin was ranked as the top-ranked upstream regulator in the comparison between IFN- $\gamma$ SP and IL10SP. These results suggest that $\beta$-catenin plays a critical role in driving the production of both IFN- $\gamma$ and IL-10 in $\mathrm{T}_{\text {reg }}$ cells, especially for IFN- $\gamma$. We also identified several upstream regulators that have been demonstrated to have critical roles in maintaining $\mathrm{T}_{\text {reg }}$ function, including $M Y B, S A T B 1$, $N F A T C 2$, and $K L F 2$, suggesting that our upstream regulator analysis provides a reliable readout.

In agreement with these findings, gene-set-enrichment analysis (GSEA) identified significant enrichment of the Wnt- $\beta$-catenin signaling pathway in IFN- $\gamma$-producing $\mathrm{T}_{\text {reg }}$ subsets (Fig. 2c). IFN- $\gamma$ SP exhibited the highest enrichment score for the Wnt- $\beta$-catenin signaling pathway. Further GSEA analysis with different gene sets also provided similar results (Supplementary Fig. 2a). Taken together, these findings indicate that Wnt- $\beta$-catenin signaling is more activated in IFN- $\gamma$-secreting $\mathrm{T}_{\text {reg }}$ cells than in other human $\mathrm{T}_{\text {reg }}$ subpopulations.

\section{$\beta$-catenin is stabilized in the IFN- $\gamma$ secreting $T_{\text {reg }}$ population}

We first confirmed that $\beta$-catenin is stabilized and transcriptionally active in IFN- $\gamma \mathrm{SP}$ compared to DN in ex vivo $T_{\text {reg }}$ cells by examining the level of Active $\beta$-catenin, the dephosphorylated form of $\beta$-catenin with established active transcriptional activity ${ }^{23}$ (Fig. 3a). Notably, the DP and IL10SP also exhibited increased Active $\beta$-catenin expression compared to DN ex vivo, suggesting that $\beta$-catenin signaling is important not only for IFN- $\gamma$ but also for IL-10 production in $\mathrm{T}_{\text {reg }}$ cells, consistent with our upstream regulator and 
enrichment analyses. To exclude the possibility that PMA plus iomomycin stimulation affected $\beta$-catenin stability, we measured Active $\beta$-catenin levels in $\mathrm{CXCR}^{+} \mathrm{T}_{\mathrm{H}} 1$-like $\mathrm{T}_{\text {reg }}$ cells, which contain most of the IFN- $\gamma$-producing $\mathrm{T}_{\text {reg }}$ cells ${ }^{24}$ without PMA plus iomomycin stimulation; these analyses confirmed that Active $\beta$-catenin expression was significantly increased in the $\mathrm{CXCR} 3^{+} \mathrm{T}_{\mathrm{H}}$ 1-like $\mathrm{T}_{\text {reg }}$ population (Fig. 3b). In agreement with these data, the downstream $\beta$-catenin target genes, $A X I N 2$ and TCF7, and the protein TCF-1 (encoded by TCF7) were upregulated in IFN- $\gamma$ SP compared to DN ex vivo (Fig. 3c, Supplementary Fig. 2b). This was consistent with previously published microarray data for IFN- $\gamma$-positive and IFN- $\gamma$-negative $\mathrm{T}_{\text {reg }}$ cells ${ }^{25}$ (Supplementary Fig. 2c).

To examine whether the in vitro model can recapitulate the ex vivo results, we assayed Active $\beta$-catenin levels on each of the $\mathrm{T}_{\text {reg }}$ subsets after four days of culture with anti-CD3 and anti-CD28 stimulation. IFN- $\gamma$-producing $\mathrm{T}_{\text {reg }}$ populations (IFN- $\gamma \mathrm{SP}$ and DP) showed higher Active $\beta$-catenin expression compared to IL10SP and DN (Fig. 3d), indicating that stabilization of $\beta$-catenin is more enhanced in IFN- $\gamma$ SP compared to IL10SP under T cells receptor (TCR) stimulation. IL-12 is an essential cytokine to induce IFN- $\gamma$-producing pathogenic $T_{\text {reg }}$ cells under TCR stimulation ${ }^{5}$. We found that upregulation of $\beta$-catenin was also observed in IL-12-induced $\mathrm{T}_{\mathrm{H}} 1$-like $\mathrm{T}_{\text {reg }}$ cells, especially in the IFN- $\gamma$-producing population (Fig. 3e). To determine if Wnt- $\beta$-catenin signaling was necessary for IFN- $\gamma$ production in $\mathrm{T}_{\mathrm{H}} 1$-like $\mathrm{T}_{\text {reg }}$ cells, we blocked $\beta$-catenin signaling with the $\beta$-catenin signaling inhibitor, PKF115-584 (PKF). $\mathrm{T}_{\text {reg }}$ cells treated with PKF exhibited a significantly reduced production of IFN- $\gamma$ (Fig. 3f, g). IL-10 production was also suppressed by PKF treatment, albeit less dramatically than IFN- $\gamma$. Knocking down the CTNNB1 gene in $\mathrm{T}_{\text {reg }}$ cells using short hairpin RNA (shRNA) (Supplementary Fig. 2d) ameliorated IL-12-induced IFN- $\gamma$ and IL-10 production (Fig. 3h, i). These data suggest that $\beta$-catenin plays a critical role in IFN- $\gamma$ and IL-10 induction in human $\mathrm{T}_{\text {reg }}$ cells, but more profoundly in IFN- $\gamma$ production under TCR stimulation.

\section{Constitutive activation of $\beta$-catenin in $T_{\text {reg }}$ cells induces Scurfy-like autoimmunity}

To ascertain the physiological relevance of $\beta$-catenin signaling in $\mathrm{T}_{\text {reg }}$ cells, we generated $\mathrm{T}_{\text {reg-specific } \beta \text {-catenin stabilized mice by crossing Foxp3-IRES-Cre mice (Foxp3Cre) }}{ }^{26}$ with $C$ tnnb1 $\Delta \mathrm{Ex} 3$ mice $^{27}$ (Supplementary Fig. 3a), where the active form of $\beta$-catenin was specifically induced in $\mathrm{T}_{\text {reg }}$ cells. In these $C$ tnnb1 $\Delta \mathrm{Ex} 3 / F o x p 3 \mathrm{Cre}$ mice, $\beta$-catenin was highly stabilized in Foxp $3^{+} \mathrm{T}_{\text {reg }}$ cells, but not on Foxp3 - non- $\mathrm{T}_{\text {reg }}$ cells (Fig. 4a, Supplementary Fig. 3b). Ctnnb1 $1 \mathrm{Ex} 3 /$ Foxp 3 Cre mice spontaneously developed a hunched posture, crusting of the ears, eyelids and tail and showed thymic atrophy, splenomegaly and lymphadenopathy (Fig. 4b). Histologic analysis demonstrated lymphocyte infiltration into several tissues, such as lung, pancreas, liver, and intestine, representing systemic inflammation in Ctnnb1 $\Delta \mathrm{Ex} 3 /$ Foxp3Cre mice (Fig. 4c). This Scurfy-like fulminant autoimmunity led to premature death within 40 days of birth with 100\% penetrance (Fig. $4 d)$.

The balance between $T_{\text {reg }}$ cells and effector $T$ cells is critical to maintain $\mathrm{T}$ cell homeostasis both in central and peripheral lymphoid tissue. The percentage of $\mathrm{T}_{\text {reg }}$ cells within thymic

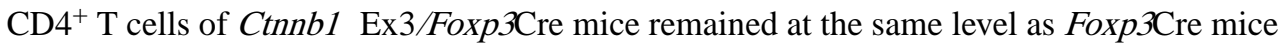


by the age of 3 weeks and even increased at the age of 5 weeks; however, the number of $\mathrm{T}_{\text {reg }}$

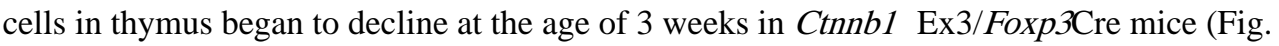
$4 \mathrm{e})$. In contrast, Ctnnb1 $1 \mathrm{Ex} 3 /$ Foxp3Cre mice displayed an increased number of $\mathrm{CD}^{+}$and $\mathrm{CD}^{+}$conventional $\mathrm{T}$ cells in secondary lymphoid organs (Fig. 4f) and higher expression of effector cytokines such as Ifng, II4, and II10, but not II17a (Supplementary Fig. 3c).

Downregulation of Rorc in both $\mathrm{T}_{\text {reg }}$ cells and conventional $\mathrm{CD} 4^{+} \mathrm{T}$ cells is the opposite for Ctnnb1 $\triangle \mathrm{Ex} 3 / C D 4 \mathrm{Cre}$ mice ${ }^{28}$, highlighting the difference between $\mathrm{T}_{\text {reg }}$ cells from

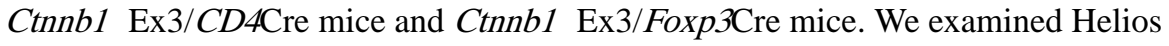
expression to characterize the functional stability of $\mathrm{T}_{\text {reg }}$ cells ${ }^{29}$, and found that Ctnnb1 $\Delta \mathrm{Ex} 3 /$ Foxp3Cre $\mathrm{T}_{\text {reg }}$ cells lost Helios expression, supporting the unstable and dysfunctional feature of Ctnnb1 $\Delta \mathrm{Ex} 3 /$ Foxp $3 \mathrm{Cre} \mathrm{T}_{\text {reg }}$ cells (Supplementary Fig. 3d). These results suggest that forced expression of a stabilized form of $\beta$-catenin in $\mathrm{T}_{\text {reg }}$ cells influences their functional stability in the periphery more than in the central compartment.

In vitro suppression assay revealed that $C$ tnnb $1 \Delta \mathrm{Ex} 3 /$ Foxp $3 \mathrm{Cre} \mathrm{T}_{\text {reg }}$ cells showed less suppressive activity compared to Foxp3Cre $\mathrm{T}_{\text {reg }}$ cells (Fig. 5a). Given that the direct interaction of $\beta$-catenin with Foxo1 has been reported ${ }^{30,31}$, we noted that the morphological and pathophysiological phenotype of Ctnnb1 $1 \mathrm{Ex} 3 /$ Foxp3Cre mice was similar to that of $\mathrm{T}_{\text {reg-specific Foxo1 depletion mice, which exhibited fulminant autoimmunity and disrupted }}$ $\mathrm{T}_{\text {reg }}$ function with aberrant IFN- $\gamma$ expression $^{32}$. To identify transcriptional changes in $\beta$ catenin stabilized $\mathrm{T}_{\text {reg }}$ cells, we measured the gene expression signature of Ctnnb1 $\Delta \mathrm{Ex} 3 /$ Foxp3Cre $\mathrm{T}_{\text {reg }}$ cells by genome-wide DNA microarrays (Fig. 5b). Further assessment with GSEA revealed similar transcriptional profiles between Ctnnb1 $\mathrm{Ex} 3 /$ Foxp $3 \mathrm{Cre} \mathrm{T}_{\text {reg }}$ cells and Foxo1-depleted $\mathrm{T}_{\text {reg }}$ cells (Supplementary Fig. 3e). In agreement with this observation, phosphorylated Foxo1 and Foxo3a were increased in Ctnnb1 $\Delta \mathrm{Ex} 3 /$ Foxp $3 \mathrm{Cre} \mathrm{T}_{\text {reg }}$ cells compared to Foxp3Cre $\mathrm{T}_{\text {reg }}$ cells (Fig. 5c). To determine whether $\beta$-catenin and Foxo1 are directly interacting with each other, we performed an in situ proximity ligation assay (PLA) on human $T_{\text {reg }}$ cells and detected the PLA signal in human $T_{\text {reg }}$ cells (Fig. 5d). Collectively, our results indicate that $\beta$-catenin regulates the pro-inflammatory $\mathrm{T}_{\mathrm{H}} 1$-skewing program in $\mathrm{T}_{\text {reg }}$ in concert with the Foxo pathway.

\section{High salt environment activates the $\beta$-catenin-SGK1-Foxo axis and produces IFN- $\gamma /$ IL-10 imbalance}

It has been shown previously that the $\mathrm{PI}_{3} \mathrm{~K}-\mathrm{AKT} 1-\mathrm{Foxo}$ axis played a pivotal role in inducing IFN- $\gamma$-producing dysfunctional $\mathrm{T}_{\text {reg }}{ }^{25}$. Furthermore, we observed that $\mathrm{p}$-Foxo1/3a and SGK1 were upregulated in Ctnnb1 $\mathrm{Ex} 3 /$ Foxp $3 \mathrm{Cre} \mathrm{T}_{\text {reg }}$ cells. To assess if the SGK1Foxo axis is activated in human $\mathrm{T}_{\text {reg }}$ subpopulations, we examined p-SGK1 and p-Foxo1 levels by flow cytometry and found that both were highly expressed in the IFN- $\boldsymbol{\gamma}$-producing $\mathrm{T}_{\text {reg }}$ population ex vivo (Supplementary Fig. 4a). Additionally, we demonstrated the direct interaction between $\beta$-catenin and Foxo1 in IFN- $\gamma$-producing human $\mathrm{T}_{\text {reg }}$ cells by using PLA (Supplementary Fig. $4 \mathrm{~b}$ ). These findings prompted us to hypothesize that activation of $\beta$-catenin is involved in high salt-induced IFN- $\gamma$ production as an upstream regulator of the SGK1-Foxo axis. Higher expression of Active $\beta$-catenin, p-SGK1, and p-Foxo1 was observed specifically in the IFN- $\gamma$-producing human $\mathrm{T}_{\text {reg }}$ subset under high salt conditions (Fig. 6a), but not in the IL-10-producing subset (Supplementary Fig. 4c). $\beta$-catenin target 
genes (AXIN2 and TCF7) and TCF-1 protein were also upregulated in human $\mathrm{T}_{\text {reg }}$ cells treated with increased salt concentration (Fig. 6b, Supplementary Fig. 4d). Additional salt treatment skewed the IL-12 induced, $\mathrm{T}_{\mathrm{H}} 1$-like $\mathrm{T}_{\text {reg }}$ to produce more IFN- $\gamma$ and less IL-10, suggesting that the high salt environment might exacerbates the IFN- $\gamma$-skewing pathogenic $\mathrm{T}_{\text {reg }}$ signature that resembles the MS- $\mathrm{T}_{\text {reg }}$ phenotype (Fig. 6c, Supplementary Fig. 4e). To determine if $\beta$-catenin activation was necessary for IFN- $\gamma$ induction under high salt conditions, we pharmacologically blocked $\beta$-catenin signaling with two different Wnt- $\beta$ catenin signaling inhibitors, PKF and IWR-1. PKF or IWR-1 significantly downregulated high salt-induced IFN- $\gamma$ expression in human $\mathrm{T}_{\text {reg }}$ cells (Fig. 6d, Supplementary Fig. 4f). These results were also observed upon genetic knock down of $C T N N B 1$ by shRNA (Fig. 6eg). Given that SGK1 is a target of $\beta$-catenin signaling ${ }^{33}$, we then tested the impact of inhibiting $\beta$-catenin signaling on SGK1 activation. PKF or IWR treatment prevented SGK1 phosphorylation under high salt stimulation in human $\mathrm{T}_{\text {reg }}$ cells (Supplementary Fig. $4 \mathrm{~g}$ ). Next, we measured the production of IFN- $\gamma$ and IL-10 and Foxo1 phosphorylation in the presence or absence of SGK1 inhibitor (GSK650394; SGK1-i). SGK1-i ameliorated high salt-induced IFN- $\gamma$ production and Foxo1 phosphorylation, but had no impact on IL-10 production (Supplementary Fig. 4h, i). These results suggest that $\beta$-catenin positively regulates salt-induced IFN- $\gamma$ expression through activation of the SGK1-Foxo axis. We extended the analysis to human effector T cells (Teff, $\mathrm{CD} 4^{+} \mathrm{CD} 25^{-}$) and Jurkat $\mathrm{T}$ cells. Both of these displayed active $\beta$-catenin signaling under high salt condition (Supplementary Fig. 5a). In Teff cells there was an imbalance of IFN- $\gamma$ and IL-10 production in agreement with our $\mathrm{T}_{\text {reg }}$ data (Supplementary Fig. 5b). In addition, we generated $\beta$-catenin-depleted Jurkat $\mathrm{T}$ cells by using CRISPR/Cas9 technology, and found that high salt-induced SGK1 and Foxo1 phosphorylation were attenuated in $\beta$-catenin knockout Jurkat $\mathrm{T}$ cells (Supplementary Fig. $5 c)$. These data, along with the evidence from non-immune cells ${ }^{34}$, supports our hypothesis that the $\beta$-catenin-SGK1-Foxo1 axis is activated by high salt stimulation.

We next explored the molecular mechanisms underlying high salt-induced $\beta$-catenin activation. First, we examined whether Wnt ligands play a role in this aberrant activation of $\beta$-catenin signaling. We used the fragment crystallizable region fused to the cysteine-rich domain of Frizzled-8 protein (Fzd8-FC), which is known to act as a scavenger of Wnt ligands, to inhibit the effect of Wnt ligands on $\mathrm{T}_{\text {reg }}$ cells. Activation of $\beta$-catenin assessed by Active $\beta$-catenin level or production of IFN- $\gamma$ and IL-10 were not affected by Fzd8-FC treatment in control or high salt conditions, suggesting the dispensable role for Wnt ligands in high salt-induced activation of $\beta$-catenin (Supplementary Fig. 6a, b). Although a salinity stress sensor has not been fully described in mammalian cells, a number of pathways contributing to the salt stress response have been identified ${ }^{34,35}$. Within these pathways, we focused on AKT kinase because it is well known to regulate $\beta$-catenin signaling via direct phosphorylation of $\beta$-catenin ${ }^{36}$ or indirectly through GSK3$\beta$, which is a negative regulator of $\beta$-catenin. Indeed, the $\mathrm{PI}_{3} \mathrm{~K}$-AKT pathway was highly enriched in the IFN- $\gamma$-producing $\mathrm{T}_{\text {reg }}$ subset and AKT phosphorylation at Ser473 was increased in IFN- $\gamma$-producing $\mathrm{T}_{\text {reg }}$ (Supplementary Fig. 6c, d). We then investigated whether $\beta$-catenin could be directly activated by AKT by examining AKT-specific phosphorylation of $\beta$-catenin (Ser522), which stabilizes $\beta$-catenin ${ }^{36}$. Phosphorylation of $\beta$-catenin (Ser522) was increased in a high salt environment and this effect was reversed by the AKT inhibitor MK2206, indicating that 
activation of AKT is responsible for stabilizing $\beta$-catenin during high salt stimulation ${ }^{34}$ (Supplementary Fig. 6e). Furthermore, we demonstrate that phosphorylation of GSK3 $\beta$ at Ser9, which is an important site of phosphorylation by AKT, was increased by high salt stimulation and that amounts of both p-AKT and p-GSK3 $\beta$ were not affected by silencing $\beta$ catenin (Supplemental Fig. 6f), suggesting both of them act upstream of $\beta$-catenin. These data indicate that AKT regulates $\beta$-catenin activation by both direct and indirect mechanisms under high salt conditions.

\section{A high salt-induced PTGER2- $\beta$-catenin loop leads to imbalance between IFN- $\gamma$ and IL-10}

Both IFN- $\gamma$ and IL-10 are upregulated in IL-12-induced $\mathrm{T}_{\mathrm{H}} 1$-like $\mathrm{T}_{\text {reg }}$ cells in a $\beta$-catenindependent manner (Fig. 3f-i). However, IL-10 expression was significantly suppressed by high salt treatment, in contrast to IFN- $\gamma$. In fact, the $\beta$-catenin-SGK1-Foxo axis was not activated in IL-10SP after high salt treatment (Supplementary Fig. 4c). Additionally, the effect of high salt on IL-10 production could not be explained by activated $\beta$-catenin signaling (Fig. 6e, f, Supplementary Fig. 4f). Thus, we hypothesized that there might exist a factor that can be uniquely induced in the high salt environment but not in IL-12-driven $T_{H} 1$ conditions, resulting in IL-10 inhibition. We compared the gene expression profiles of $\mathrm{T}_{\text {reg }}$ cells between control media and IL-12 supplemented media $\left(\mathrm{T}_{\mathrm{H}} 1\right)$, and also between control media and $\mathrm{NaCl}$ supplemented media $(\mathrm{NaCl})$. Among the group of differentially expressed genes in each comparison, we identified six genes that were upregulated in high salt conditions but downregulated in $\mathrm{T}_{\mathrm{H}} 1$ conditions, and four genes that were regulated in the opposite direction, which are potentially able to account for the high salt-induced IFN$\gamma:$ IL10 imbalance (Fig. 7a).

PTGER2 is known to regulate the production of cytokines in a context-dependent manner $37,38,39,40,41$, and the action of PTGER2 on cytokine production, especially IFN- $\gamma$ production in $\mathrm{T}$ cells, was affected by the strength of $\mathrm{PI}_{3} \mathrm{~K}$-AKT signaling ${ }^{42}$. Since we have observed a role for PTGER2 in promoting the pathogenic phenotype by modulating IFN$\gamma$ :IL10 balance in $\mathrm{T}_{\mathrm{H}} 17$ cells $\mathrm{s}^{39}$ and high salt treatment induces a pathogenic $\mathrm{T}_{\mathrm{H}} 17$ cell signature, we hypothesized that PTGER2 regulates the IFN- $\gamma$ :IL-10 balance in salt stimulated $\mathrm{T}_{\text {reg }}$ cells. Indeed, PTGER 2 was upregulated after high salt treatment in human $\mathrm{T}_{\text {reg }}$ cells and $\mathrm{T}_{\mathrm{H}} 17$ cells (Fig. $7 \mathrm{~b}$ ) and was highly expressed in IFN- $\gamma \mathrm{SP}$ compared to IL10SP (Supplementary Fig. 7a).

Given the evidence of a positive relationship between $\beta$-catenin signaling and PTGER2 ${ }^{43,} 44$, we investigated whether $\beta$-catenin and PTGER2 build an autoregulatory loop during chronic high salt exposure. We used Jurkat $\mathrm{T}$ cells, and demonstrated that high salt-induced PTGER2 was suppressed by genetic deletion of CTNNB1 (Supplementary Fig. 7b) and that PTGER2 knockdown could partially ameliorate high salt-induced $\beta$-catenin activation (Supplementary Fig. 7c). These results suggest the presence of a $\beta$-catenin-PTGER2 feedforward loop under high salt conditions. PTGER2 silencing abolished the high salt-induced IFN- $\gamma$ :IL-10 imbalance on human $T_{\text {reg }}$ cells, and eliminated the high salt-induced activation of $\beta$-catenin in IFN- $\gamma$ SP, while it did not affect Active $\beta$-catenin level in IL10SP (Fig. 7c-e), suggesting that high salt-induced IFN- $\gamma$ depends on the PTGER2- $\beta$-catenin loop, but IL-10 suppression by high salt is dependent on PTGER2 per se but not on $\beta$-catenin. 
We further investigated if the high salt-induced PTGER2- $\beta$-catenin loop could be amplified in cells where AKT is activated, such as in IFN- $\gamma$ producing $\mathrm{T}_{\text {reg }}$, but not in the cells with lower AKT activity, such as IL-10 producing $\mathrm{T}_{\text {reg }}$. We then tested the impact of modulating AKT signaling on IFN- $\gamma$ and IL-10 production in $\mathrm{T}_{\text {reg }}$ cells under high salt conditions via increasing CD28 co-stimulation. High salt-induced IFN- $\gamma$ production was boosted by strengthening AKT signaling with higher CD28 co-stimulation (Supplementary Fig. 7d) ${ }^{42}$. By contrast, high salt-induced IL-10 inhibition was not altered. Together, these data indicated that high salt induces a positive feedback loop between $\beta$-catenin and PTGER2 in conjunction with activated AKT status, resulting in amplification of IFN- $\gamma$ production in $\mathrm{T}_{\text {reg }}$ cells.

\section{Stabilized $\beta$-catenin is observed in $\mathrm{T}_{\text {reg }}$ cells from mice fed a high salt diet and MS patients}

To examine if $\beta$-catenin is stabilized under high salt conditions in vivo, we fed wild type mice with either a normal salt diet (NSD), containing $0.4 \%$ of $\mathrm{NaCl}$, or a HSD, containing $4 \% \mathrm{NaCl}$, and assayed $\beta$-catenin expression on $\mathrm{T}_{\text {reg }}$ cells. We found that $\beta$-catenin and phosphorylated Foxo1/3a/4, assayed by a monoclonal antibody for phosphorylation sites on Foxp1 (Thr24), Foxo3a (Thr32), and Foxo4 (Thr28), were increased in $\mathrm{T}_{\text {reg }}$ cells from HSD mice (Fig. 8a). Next, we determined if $\beta$-catenin is more stabilized in MS- $\mathrm{T}_{\text {reg }}$ as compared to $T_{\text {reg }}$ cells from healthy subjects. The level of Active $\beta$-catenin in IFN- $\gamma$ producing $T_{\text {reg }}$ was increased in MS patients compared to healthy subjects (Fig. 8b). We also found a positive correlation between IFN- $\gamma$ production and the level of Active $\beta$-catenin in MS-T $\mathrm{T}_{\text {reg }}$ but not in healthy subjects (Fig. 8c). Furthermore, to investigate the link between PTGER2

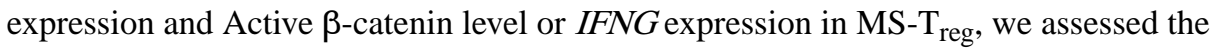
expression of these factors in $\mathrm{T}_{\text {reg }}$ cells from healthy subjects and MS patients. Notably, higher expression of PTGER 2 and Active $\beta$-catenin level are correlated with IFNG expression in MS- $\mathrm{T}_{\text {reg }}$ but not in $\mathrm{T}_{\text {reg }}$ cells from healthy subjects (Fig. 8d, e). These findings provide in vivo evidence to support our hypothesis that the PTGER2- $\beta$-catenin loop plays an important role in the salt-induced malfunction of $\mathrm{T}_{\text {reg }}$ cells and links this salt signature to the pathogenic profile of MS- $\mathrm{T}_{\text {reg }}$ (Supplementary Fig. 8).

\section{Discussion}

Loss of Foxp $3^{+}$regulatory $\mathrm{T}$ cell function is associated with a number of autoimmune diseases, and previous works have linked environment factors to autoimmunity through affecting $\mathrm{T}_{\text {reg }}$ cell homeostasis. Here we extend this concept yet also describe a novel molecular mechanism using both murine and human system. Our results demonstrate a novel role of $\beta$-catenin as a regulatory molecule for $\mathrm{T}_{\text {reg }}$ functional plasticity and also provide molecular mechanisms that link high salt environment to autoimmune disease.

Our transcriptional profiling of human $\mathrm{T}_{\text {reg }}$ subsets based on IFN- $\gamma$ and IL-10 production provides new insights into $T_{\text {reg }}$ heterogeneity. We identify $\beta$-catenin as a key regulator and demonstrate its role in skewing $\mathrm{T}_{\text {reg }}$ into a dysfunctional state in human $\mathrm{T}_{\text {reg }}$ cells and in murine models. Although several studies have demonstrated the role of $\beta$-catenin in $T_{\text {reg }}$ cells, it is still unknown how $\beta$-catenin contributes to $T_{\text {reg }}$ function and the effector cytokine signature. One study demonstrated $\beta$-catenin as an anti-inflammatory factor in the context of 
generating long-lived suppressive $\mathrm{T}_{\text {reg }}$ cells via anti-apoptotic gene induction ${ }^{45}$, and two previous studies showed that activation of $\beta$-catenin provokes $T_{\text {reg }}$ dysfunction, leading to exaggerated colitis in a murine mode ${ }^{28,46}$. We show that $\mathrm{T}_{\text {reg }}$-specific stabilization of $\beta$ catenin resulted in loss of suppressive properties of $\mathrm{T}_{\text {reg }}$ cells and induced a lethal Scurfylike phenotype in mice, which is consistent with the latter aspect. We believe our Foxp3-Cre-

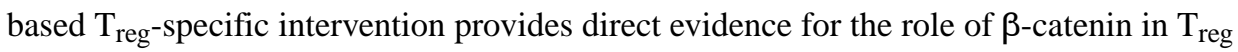
cells.

The incidence of autoimmune diseases has been increasing in the last half century, which cannot be explained by genetic adaptation. Thus, there is great interest in studying the interplay between genetic risks and environmental triggers ${ }^{47}$. Among several environmental triggers, a high salt diet might increases the incidence of autoimmune diseases, though this as yet requires further epidemiologic investigations ${ }^{48}$. Previous studies have shown that higher salt concentration affects on $\mathrm{T}_{\mathrm{H}} 17$ cell development and $\mathrm{T}_{\text {reg }}$ stability, manifest by aberrant IFN- $\gamma$ production ${ }^{16}$. Of note, our findings that IFN- $\gamma$ :IL-10 imbalance is observed not only in MS- $\mathrm{T}_{\text {reg }}$ cells but also under high salt condition suggested that the salt-induced signature may overlap with the MS pathogenic profile. The importance of IFN- $\gamma$ :IL-10 in the context of salt-induced immune alteration was supported by a previous study showing that increased sodium content in colon tissue of HSD mice resulted in excessive inflammation in IBD models ${ }^{18}$. Interestingly, $\beta$-catenin signaling was activated in both $\mathrm{T}_{\text {reg }}$ and $\mathrm{T}_{\mathrm{H}} 17$ cells under stimulation with high salt (data not shown). Furthermore, here we demonstrate that PTGER2 accounts for high salt-induced IFN- $\gamma$ :IL-10 imbalance in $\mathrm{T}_{\text {reg }}$ cells by creating a positive feed forward loop with $\beta$-catenin. Given that $\mathrm{T}_{\text {reg }}$ cells can produce PGE2 ${ }^{49}$ and that PGE2 is enriched in EAE lesions ${ }^{50}$, PGE2-PTGER2 signaling could be amplified in $\mathrm{T}_{\text {reg }}$ cells under high salt conditions and also in the MS lesion. However, the role of PGE2 in EAE and MS remains unclear and further investigation is needed.

In summary, we provide genome-wide transcriptomic profiles of human ex vivo $\mathrm{T}_{\text {reg }}$ subpopulations, which unveil the heterogeneity of $\mathrm{T}_{\text {reg }}$ cells in terms of IFN- $\gamma$ and IL-10 production. Aberrant $\beta$-catenin activation modulates $T_{\text {reg }}$ cytokine plasticity and integrity in both human and murine $T_{\text {reg }}$ cells. Under the high salt environment, this effect occurs in conjunction with upregulation of PTGER2, resulted in establishing the feed-forward loop between PTGER2 and $\beta$-catenin. Of note, $T_{\text {reg }}$ cells from MS patients display positive correlations among IFN- $\gamma$ production, PTGER 2 expression, and Active $\beta$-catenin level, which are not observed in $\mathrm{T}_{\text {reg }}$ cells from healthy subjects. Together, our study in humans with autoimmune disease and confirmed in mouse models indicates that the PTGER2- $\beta$ catenin axis serves as a bridge between environmental factors and autoimmune disease by modulating $\mathrm{T}_{\text {reg }}$ properties.

\section{Methods}

\section{Study subjects}

Peripheral blood was drawn from healthy individuals and patients with MS after informed consent and approval by the Institutional Review Board at Yale University. The patients were diagnosed with either Clinically Isolated Syndrome (CIS) or Relapsing-Remitting MS 
(RRMS) by 2010 MacDonald Criteria and were not treated with any immunomodulatory therapy at the time of the blood draw. All experiments conformed to the principles set out in the WMA Declaration of Helsinki and the Department of Health and Human Services Belmont Report. Clinical characteristics of evaluated MS patients are listed in Supplementary Table 2 .

Mice

C57/BL6/J mice were purchased from the Jackson Laboratory or CLEA Japan. FIC mice ${ }^{26}$, and $C t n n b 1 \Delta \mathrm{Ex} 3$ mice $^{27}$ have been described, and mice backcrossed into the C57/BL6/J

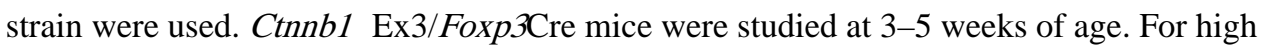
salt diet (HSD) experiments, six-week-old male wild type mice were fed with normal chow (control group) or sodium-rich chow containing 4\% $\mathrm{NaCl}$ (Research Diets; HSD group) with normal tap water for 3 weeks. Cells were isolated from the spleen and/or mesenteric lymph nodes and $\mathrm{T}_{\text {reg }}$ cells were analyzed by flow cytometry. All experiments were approved by the University of Tokyo Ethics Committee for Animal Experiments and strictly adhered to the guidelines for animal experiments of the University of Tokyo.

\section{Human T cell isolation and culture}

Peripheral blood mononuclear cells (PBMCs) were isolated from donors by Ficoll-Paque PLUS (GE Healthcare) or Lymphoprep (Stemcell) gradient centrifugation. Total CD4 ${ }^{+} \mathrm{T}$ cells were isolated by negative magnetic selection using a CD4 $\mathrm{T}$ cell isolation kit (Stemcell) and $\mathrm{CD} 4{ }^{+} \mathrm{CD} 25^{\text {hi }} \mathrm{CD} 127^{\text {lo-neg }} \mathrm{CD} 45 \mathrm{RO}^{+} \mathrm{T}_{\text {reg }}$ cells were sorted on a FACS Aria (BD

Biosciences). $T_{\text {reg }}$ cells were cultured in RPMI 1640 medium supplemented with 5\% Human serum, $2 \mathrm{nM}$ L-glutamine, $5 \mathrm{mM}$ HEPES, and $100 \mathrm{U} / \mathrm{ml}$ penicillin, $100 \mu \mathrm{g} / \mathrm{ml}$ streptomycin, $0.5 \mathrm{mM}$ sodium pyruvate, $0.05 \mathrm{mM}$ nonessential amino acids, and $5 \%$ human $\mathrm{AB}$ serum (Gemini Bio-Products). 96-well round bottom plates (Corning) were pre-coated with antihuman CD3 (UCHT1) $(1-2 \mu \mathrm{g} / \mathrm{ml})$ and used for $\mathrm{T}_{\text {reg }}$ in vitro culture with soluble antihuman CD28 (28.2) (1-5 $\mu \mathrm{g} / \mathrm{ml})$ (BD Bioscience) and human IL-2 (50 U/ml). Human IL-2 was obtained through the AIDS Research and Reference Reagent Program, Division of AIDS, National Institute of Allergy and Infectious Diseases (NIAID), National Institutes of Health (NIH). $\mathrm{T}_{\mathrm{H}} 1-\mathrm{T}_{\text {reg }}$ cells were induced with human recombinant IL-12 $(20 \mathrm{ng} / \mathrm{ml})$ (R\&D). The Wnt/ $\beta$-catenin inhibitor PKF115-584 (Tocris) was used at $200 \mathrm{nM}$ and IWR-1 (Tocris) was used at $20 \mu \mathrm{M}$. SGK1 inhibitor GSK650394 (Tocris) was used at $10 \mu \mathrm{M}$. AKT inhibitor MK2206 (Tocris) was used at $5 \mu \mathrm{M}$. Frizzled 8 FC chimera protein (R\&D) was used at $500 \mathrm{ng} / \mathrm{ml}$.

\section{Suppression assay}

$\mathrm{CD} 4{ }^{+} \mathrm{CD} 25^{+} \mathrm{T}_{\text {reg }}$ cells and $\mathrm{CD} 4{ }^{+} \mathrm{CD} 25-\mathrm{T}$ responder cells were isolated from spleen and

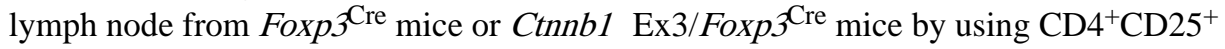
Regulatory T Cell Isolation Kit (Miltenyi Biotec) and were sorted on a FACS Aria (BD Biosciences). T responder cells were labeled with CFSE and then co-cultured with $\mathrm{T}_{\text {reg }}$ cells $\left(5 \times 10^{4}\right)$ at 1:1 ratio in RPMI 1640 medium supplemented with $10 \%$ FBS (HyClone), 50 $\mu \mathrm{M}$ 2-Mercaptoethanol (Sigma-Aldrich), 1x GlutaMAX, $50 \mathrm{U} / \mathrm{ml}$ penicillin, and $100 \mu \mathrm{g} / \mathrm{ml}$ streptomycin with Dynabeads Mouse T-Activator CD3/CD28 at 2:1 bead-to-cell ratio. The 
proliferation of $\mathrm{T}$ responder cells was determined at day 4 by FACS on a Verse instrument (BD Bioscience).

\section{Quantitative PCR}

Total RNA was extracted using RNeasy Micro Kit (QIAGEN), or ZR-96 Quick-RNA kit (Zymo Research), according to the manufacturer's instructions. RNA was treated with DNase and reverse transcribed using TaqMan Reverse Transcription Reagents (Applied Biosystems) or SuperScript IV VILO Master Mix (Invitrogen). cDNAs were amplified with Taqman probes (Taqman Gene Expression Arrays) and TaqMan Fast Advanced Master Mix on a StepOne Real-Time PCR System (Applied Biosystems) according to the manufacturer's instructions. mRNA expression was measured relative to B2M expression.

\section{Flow cytometry analysis}

Single-cell suspensions were prepared from PBMCs or mouse tissues and stained with fixable viability dye for $10 \mathrm{~min}$ at RT, followed by staining with surface antibodies for 30 min at $4^{\circ} \mathrm{C}$. For intracellular staining, cells were fixed and permeabilized with the Foxp3 Fix/Perm buffer set (eBioscience) for $1 \mathrm{~h}$ at $4^{\circ} \mathrm{C}$, followed by staining with intracellular antibodies. For cytokine staining, cells were stimulated with PMA $(50 \mathrm{ng} / \mathrm{ml})$ and ionomycin (for ex vivo $T_{\text {reg }}$ cells; $1000 \mathrm{ng} / \mathrm{ml}$, for in vitro cultured $T_{\text {reg }}$ cells; $250 \mathrm{ng} / \mathrm{ml}$ ) in the presence of GolgiPlug (BD Bioscience) for $4 \mathrm{~h}$ at $37^{\circ} \mathrm{C}$. Antibodies and reagents used for flow cytometric analysis are listed as follows: for human samples; anti-CD4 (RPA-T4), antiCD25 (MA251), anti-CD127 (HIL-7R-M21), anti-CD45RO (UCHL1), anti-IFN- $\gamma$ (B27), anti- $\beta$-catenin (14/Beta-Catenin), anti-TCF1 (S33-966), PE-Cy ${ }^{\mathrm{TM}} 7$ Streptavidin from BD Bioscience, anti-IL-10 (JES3-9D7), anti-Tbet (4B10) from BioLegend, anti-phospho Foxo1 (S256) polyclonal, anti-phospho SGK1 (T256) polyclonal (from Bioss), anti-phospho $\beta$ catenin (Ser522) (D8E11), anti-phospho AKT (Ser473) (D9E), anti-phospho GSK3 $\beta$ (Ser9) (D85E12), anti-Foxo1 (C29H4) from CST, anti-IFN- $\gamma$ (4S.B3), anti-Foxp3 (PCH101) from eBioscience, anti-active $\beta$-catenin (8E7) from Millipore, IFN- $\gamma$ secretion assay (APC), IL-10 secretion assay (PE) from Miltenyi, for mice samples; anti-Foxp3 (FJK-16s), antiCD3 (145-2C11), anti-CD4 (RM4-5), anti-CD8 (53-6.7), anti-GATA3 (TWAJ), anti-RORgt (B2D) from eBioscience, anti-Helios (22F6) from BioLegend, anti-phospho Foxo1 (S256) (E1F7T), anti-phospho Foxo3a (Ser253) (D18H8), anti-phospho Foxo1(T24)/3a(T32)/ 4(T28) (4G6) from CST, anti-SGK1 (Y238) (from Abcam), for both human and mice samples; Zombie Aqua ${ }^{\mathrm{TM}}$ Fixable Viability dye from BioLegend. Stained samples were analyzed with a BD FACS Verse or an LSR Fortessa flow cytometer (BD Bioscience). Data were analyzed with FlowJo software (Treestar).

\section{RNA-seq library preparation and data analysis}

Preparation of cells for RNA-seq: For the ex vivo $T_{\text {reg }}$ subpopulations, $\mathrm{CD} 4{ }^{+} \mathrm{CD} 25$ hiCD127lo-negCD45RO ${ }^{+}$memory $\mathrm{T}_{\text {reg }}$ cells from healthy donors were sorted and immediately stimulated with PMA $(50 \mathrm{ng} / \mathrm{ml})$ and iomomycin $(1000 \mathrm{ng} / \mathrm{ml})$ for $4 \mathrm{~h}$. By combining IFN- $\gamma$ secretion assay (APC) and IL-10 secretion assay (PE) (Miltenyi), $\mathrm{T}_{\text {reg }}$ cells were labeled based on the expression of IFN- $\gamma$ and IL-10. To avoid RNA degradation, cells were kept in CellCover (Anacyte) before a second round of sorting. For in vitro 
cultured $\mathrm{T}_{\text {reg }}$ cells in $\mathrm{T}_{\mathrm{H}} 1$ or high salt conditions, $\mathrm{mT}_{\text {reg }}$ cells were cultured in each condition for four days as described. Cells were harvested and immediately processed for cDNA preparation. Samples were collected from four healthy subjects for identification of the $\mathrm{T}_{\mathrm{H}} 1$ signature and five healthy subjects for identification of the high salt signature.

cDNA and library preparation and sequencing: cDNAs were generated directly from resorted and harvested cells using the SMART-Seq v4 Ultra Low Input RNA Kit for sequencing (Takara/Clontech). Barcoded libraries were generated by the Nextera XT DNA Library Preparation kit (Illumina) and sequenced with a $2 \times 100$ bp paired-end protocol on the HiSeq 2000 Sequencing System (Illumina).

RNA-seq data analysis: RNA-seq analysis was performed using Partek flow (v6.6). First, RNA-seq reads were trimmed and mapped to the hg19 genome reference using STAR (2.5.0e). Aligned reads were quantified to the gene level using Partek's E/M algorithm and gene annotation from Ensembl release 75. Gene-level quantitations were normalized by dividing the gene counts by the total number of reads, following by addition of a small offset (0.001). The offset was added to enable $\log 2$ transformation and the value of the offset was determined by exploring the data distribution. Differential expression was assessed by fitting Partek's log-normal model with shrinkage (comparable in performance to limma-trend). Genes having geometric mean below 1.0 were removed from the analysis.

For ex vivo $\mathrm{T}_{\text {reg }}$ subpopulation data, differentially expressed genes (Fold change $>1.5, P$ value $<0.05$ ) were used for functional analysis using IPA and upstream regulator analysis (https://www.qiagenbioinformatics.com/products/ingenuity-pathway-analysis/). Gene set enrichment analysis was performed on normalized gene expression counts of RNA-seq data or microarray data as described previously.

For in vitro $\mathrm{T}_{\mathrm{H}} 1-\mathrm{T}_{\text {reg }}$ and high salt $\mathrm{T}_{\text {reg }}$ data, differentially expressed genes (Fold change > $2, P$ value $<0.05)$ were used.

\section{Microarray}

For the Oligo DNA microarray analysis, total RNA samples were extracted from sorted $\mathrm{CD} 4{ }^{+} \mathrm{CD} 25^{\mathrm{hi}} \mathrm{T}_{\text {reg }}$ cells of Foxp3Cre mice or Ctnnb1 $\Delta \mathrm{Ex} 3 /$ Foxp3Cre mice. Microarray analysis was performed with a 3D-Gene Mouse Oligo chip 24k (Toray Industries Inc., Tokyo, Japan). Total RNA was labeled with Cy5 by using the Amino Allyl MessageAMP II aRNA Amplification Kit (Applied Biosystems). The Cy5-labeled aRNA pools were mixed with hybridization buffer, and hybridized for $16 \mathrm{~h}$. The hybridization signals were obtained by using a 3D-Gene Scanner and processed by 3D-Gene Extraction software (Toray Industries Inc.). Detected signals for each gene were normalized with the global normalization method (the median of the detected signal intensity was adjusted to 25).

\section{Histology}

Mouse tissues were fixed in Ufix (Sakura Finetek Japan) and embedded in paraffin. 6- $\mu \mathrm{m}$ tissue sections were stained with haematoxylin and eosin. 


\section{Lentiviral transduction for shRNA gene silencing and CRISPR/Cas9-mediated gene deletion}

Lentiviral plasmids encoding shRNAs were obtained from Sigma-Aldrich and all-in-one vectors carrying $C T N N B 1$ sgRNA/Cas9 with GFP reporter were obtained from Applied Biological Materials. Each plasmid was transformed into One Shot ${ }^{\circledR}$ Stbl $3^{\mathrm{TM}}$ chemically competent cells (Invitrogen) and purified by ZymoPURE plasmid Maxiprep kit (Zymo research). Lentiviral pseudoparticles were obtained after plasmid transfection of 293FT cells using Lipofectamine 2000 (Invitrogen). The lentivirus-containing media was harvested 48 or $72 \mathrm{~h}$ after transfection and concentrated 40 - 50 times using Lenti-X concentrator (Takara Clontech). Sorted $\mathrm{T}_{\text {reg }}$ cells were stimulated with plate-bound anti-CD3 $(1 \mu \mathrm{g} / \mathrm{ml})$ and soluble anti-CD28 $(1 \mu \mathrm{g} / \mathrm{ml})$ for $24 \mathrm{~h}$ and transduced with lentiviral particles by spinfection $\left(1000 \times g\right.$ for $90 \mathrm{~min}$ at $\left.32^{\circ} \mathrm{C}\right)$ in the presence of Polybrene $(5 \mu \mathrm{g} / \mathrm{ml})$ on the plates coated with Retronectin $(50 \mu \mathrm{g} / \mathrm{ml})$ (Takara/Clontech) and anti-CD3 $(1-2 \mu \mathrm{g} / \mathrm{ml})$. Human Jurkat T cells were directly transduced with lentiviral particles by spinfection. Five days after transduction, cells were sorted on the basis of expression of GFP. GFP expressing human Jurkat $\mathrm{T}$ cells were further purified by FACS at least three times before using for experiments.

\section{Proximity ligation assay (PLA)}

PLA was performed with Duolink In Situ Detection Reagents Orange (Sigma) according to the manufacturer's recommendation with minor modifications. $\mathrm{T}_{\text {reg }}$ cells were cultured for four days and harvested, and cells were fixed with $2 \%$ paraformaldehyde for $10 \mathrm{~min}$ at RT. Fixed cells were incubated in Foxp3 Fix/Perm buffer set for 30 min at $4^{\circ} \mathrm{C}$, followed by staining with mouse anti- $\beta$-catenin (14/Beta-Catenin) and rabbit anti-Foxo1 (C29H4) for $1 \mathrm{~h}$ at RT in Foxp3 staining buffer. Cells were washed and stained in Foxp3 staining buffer with the secondary mouse PLUS and rabbit MINUS antibodies for $30 \mathrm{~min}$ at RT. Cells were washed in TBS $(0.01 \mathrm{M}$ Tris, $0.15 \mathrm{M} \mathrm{NaCl})$ with $0.5 \%$ BSA and the ligation reaction was performed at $37^{\circ} \mathrm{C}$ for $30 \mathrm{~min}$, followed by the amplification reaction at $37^{\circ} \mathrm{C}$ for $100 \mathrm{~min}$. Cells were washed in TBS $(0.2 \mathrm{M}$ Tris, $0.1 \mathrm{M} \mathrm{NaCl})$ with $0.5 \%$ BSA and stained with antiFoxp3 (PCH101) or anti-IFN- $\gamma$ (B27) antibody for $30 \mathrm{~min}$ at $4{ }^{\circ} \mathrm{C}$. Cells were analyzed with a 60x or 100x objective on a Leica DM6000 CS confocal microscope.

\section{Statistical analysis}

All statistical analyses were performed using GraphPad Prism 6 (GraphPad Software). Detailed information about statistical analysis, including tests and values used, is provided in the figure legends. Values of $P<0.05$ or less were considered significant.

\section{Supplementary Material}

Refer to Web version on PubMed Central for supplementary material.

\section{Acknowledgements}

We thank L. Devine, C. Wang, and H. Tomita for cell sorting, and E. Cheng and M. Zhang for preparation of the RNA-seq library, K. Tanaka for microscopic imaging, and M. Shimizu, H. Taniwaki, and N. Yamanaka for technical support. FIC mice were a generous gift from S. Sakaguchi (Osaka University). This work was supported by grants 
from the Uehara Memorial Foundation Research Fellowship, MSD Life Science Foundation Research Fellowship, LEGEND Study Abroad Grant from BioLegend and Tomy Digital Biology (to T.S.), the Ministry of Education, Culture, Sports, Science and Technology (MEXT); JSPS KAKENHI (Grant Number 21229010), the Core Research for Evolutional Science and Technology (CREST) program from the Japan Science and Technology Agency (to I.K.), National Institutes of Health Grants (P01 AI045757, U19 AI046130, U19 AI070352, and P01 AI039671), and the Nancy Taylor Foundation for Chronic Diseases (to D.A.H.). RNA sequencing service was conducted at Yale Stem Cell Center Genomics Core facility that was supported by the Connecticut Regenerative Medicine Research Fund and the Li Ka Shing Foundation.

\section{Reference}

1. Sakaguchi S, Ono M, Setoguchi R, Yagi H, Hori S, Fehervari Z, et al. Foxp3+ CD25+ CD4+ natural regulatory T cells in dominant self-tolerance and autoimmune disease. Immunol Rev 2006, 212 827. [PubMed: 16903903]

2. Viglietta V, Baecher-Allan C, Weiner HL, Hafler DA. Loss of functional suppression by CD4+CD25+ regulatory T cells in patients with multiple sclerosis. J Exp Med 2004, 199(7) 971979. [PubMed: 15067033]

3. Buckner JH. Mechanisms of impaired regulation by CD4(+)CD25(+)FOXP3(+) regulatory T cells in human autoimmune diseases. Nat Rev Immunol 2010, 10(12) 849-859. [PubMed: 21107346]

4. Miyara M, Yoshioka Y, Kitoh A, Shima T, Wing K, Niwa A, et al. Functional delineation and differentiation dynamics of human CD4+ T cells expressing the FoxP3 transcription factor. Immunity 2009, 30(6) 899-911. [PubMed: 19464196]

5. Dominguez-Villar M, Baecher-Allan CM, Hafler DA. Identification of T helper type 1-like, Foxp3+ regulatory T cells in human autoimmune disease. Nat Med 2011, 17(6) 673-675. [PubMed: 21540856]

6. McClymont SA, Putnam AL, Lee MR, Esensten JH, Liu W, Hulme MA, et al. Plasticity of human regulatory $\mathrm{T}$ cells in healthy subjects and patients with type 1 diabetes. J Immunol 2011, 186(7) 3918-3926. [PubMed: 21368230]

7. Lowther DE, Goods BA, Lucca LE, Lerner BA, Raddassi K, van Dijk D, et al. PD-1 marks dysfunctional regulatory T cells in malignant gliomas. JCI Insight 2016, 1(5).

8. Rubtsov YP, Rasmussen JP, Chi EY, Fontenot J, Castelli L, Ye X, et al. Regulatory T cell-derived interleukin-10 limits inflammation at environmental interfaces. Immunity 2008, 28(4) 546-558. [PubMed: 18387831]

9. Laidlaw BJ, Cui W, Amezquita RA, Gray SM, Guan T, Lu Y, et al. Production of IL-10 by CD4(+) regulatory $\mathrm{T}$ cells during the resolution of infection promotes the maturation of memory CD8(+) T cells. Nat Immunol 2015, 16(8) 871-879. [PubMed: 26147684]

10. Marson A, Housley WJ, Hafler DA. Genetic basis of autoimmunity. J Clin Invest 2015, 125(6) 2234-2241. [PubMed: 26030227]

11. International Multiple Sclerosis Genetics C, Hafler DA, Compston A, Sawcer S, Lander ES, Daly MJ, et al. Risk alleles for multiple sclerosis identified by a genomewide study. N Engl J Med 2007, 357(9) 851-862. [PubMed: 17660530]

12. International Multiple Sclerosis Genetics C, Patsopoulos N, Baranzini SE, Santaniello A, Cotsapas C, Wong G, et al. The Multiple Sclerosis Genomic Map: Role of peripheral immune cells and resident microglia in susceptibility. bioRxiv 2017, https://www.biorxiv.org/content/early/ 2017/07/13/143933.

13. Olsson T, Barcellos LF, Alfredsson L. Interactions between genetic, lifestyle and environmental risk factors for multiple sclerosis. Nat Rev Neurol 2017, 13(1): 25-36. [PubMed: 27934854]

14. Kleinewietfeld M, Manzel A, Titze J, Kvakan H, Yosef N, Linker RA, et al. Sodium chloride drives autoimmune disease by the induction of pathogenic TH17 cells. Nature 2013, 496(7446): 518 522. [PubMed: 23467095]

15. Wu C, Yosef N, Thalhamer T, Zhu C, Xiao S, Kishi Y, et al. Induction of pathogenic TH17 cells by inducible salt-sensing kinase SGK1. Nature 2013, 496(7446): 513-517. [PubMed: 23467085]

16. Hernandez AL, Kitz A, Wu C, Lowther DE, Rodriguez DM, Vudattu N, et al. Sodium chloride inhibits the suppressive function of FOXP3+ regulatory T cells. J Clin Invest 2015, 125(11): 42124222. [PubMed: 26524592] 
17. Wei Y, Lu C, Chen J, Cui G, Wang L, Yu T, et al. High salt diet stimulates gut Th17 response and exacerbates TNBS-induced colitis in mice. Oncotarget 2017, 8(1): 70-82. [PubMed: 27926535]

18. Tubbs AL, Liu B, Rogers TD, Sartor RB, Miao EA. Dietary Salt Exacerbates Experimental Colitis. J Immunol 2017, 199(3): 1051-1059. [PubMed: 28637899]

19. Paling D, Solanky BS, Riemer F, Tozer DJ, Wheeler-Kingshott CA, Kapoor R, et al. Sodium accumulation is associated with disability and a progressive course in multiple sclerosis. Brain 2013, 136(Pt 7): 2305-2317. [PubMed: 23801742]

20. Fitzgerald KC, Munger KL, Hartung HP, Freedman MS, Montalban X, Edan G, et al. Sodium intake and multiple sclerosis activity and progression in BENEFIT. Ann Neurol 2017, 82(1): 20 29. [PubMed: 28556498]

21. Clevers H Wnt/beta-catenin signaling in development and disease. Cell 2006, 127(3): 469-480. [PubMed: 17081971]

22. Naito AT, Sumida T, Nomura S, Liu ML, Higo T, Nakagawa A, et al. Complement C1q activates canonical Wnt signaling and promotes aging-related phenotypes. Cell 2012, 149(6): 1298-1313. [PubMed: 22682250]

23. Staal FJ, van Noort M, Strous GJ, Clevers HC. Wnt signals are transmitted through N-terminally dephosphorylated beta-catenin. EMBO Rep 2002, 3(1): 63-68. [PubMed: 11751573]

24. Duhen T, Duhen R, Lanzavecchia A, Sallusto F, Campbell DJ. Functionally distinct subsets of human FOXP3+ Treg cells that phenotypically mirror effector Th cells. Blood 2012, 119(19): 4430-4440. [PubMed: 22438251]

25. Kitz A, de Marcken M, Gautron AS, Mitrovic M, Hafler DA, Dominguez-Villar M. AKT isoforms modulate Th1-like Treg generation and function in human autoimmune disease. EMBO Rep 2016, 17(8): 1169-1183. [PubMed: 27312110]

26. Wing K, Onishi Y, Prieto-Martin P, Yamaguchi T, Miyara M, Fehervari Z, et al. CTLA-4 control over Foxp3+ regulatory T cell function. Science 2008, 322(5899): 271-275. [PubMed: 18845758]

27. Harada N, Tamai Y, Ishikawa T, Sauer B, Takaku K, Oshima M, et al. Intestinal polyposis in mice with a dominant stable mutation of the beta-catenin gene. EMBO J 1999, 18(21): 5931-5942. [PubMed: 10545105]

28. Keerthivasan S, Aghajani K, Dose M, Molinero L, Khan MW, Venkateswaran V, et al. beta-Catenin promotes colitis and colon cancer through imprinting of proinflammatory properties in T cells. Sci Transl Med 2014, 6(225): 225ra228.

29. Sebastian M, Lopez-Ocasio M, Metidji A, Rieder SA, Shevach EM, Thornton AM. Helios Controls a Limited Subset of Regulatory T Cell Functions. J Immunol 2016, 196(1): 144-155. [PubMed: 26582951]

30. Essers MA, de Vries-Smits LM, Barker N, Polderman PE, Burgering BM, Korswagen HC.

Functional interaction between beta-catenin and FOXO in oxidative stress signaling. Science 2005, 308(5725): 1181-1184. [PubMed: 15905404]

31. Okada K, Naito AT, Higo T, Nakagawa A, Shibamoto M, Sakai T, et al. Wnt/beta-Catenin Signaling Contributes to Skeletal Myopathy in Heart Failure via Direct Interaction With Forkhead Box O. Circ Heart Fail 2015, 8(4): 799-808. [PubMed: 26038536]

32. Ouyang W, Liao W, Luo CT, Yin N, Huse M, Kim MV, et al. Novel Foxo1-dependent transcriptional programs control T(reg) cell function. Nature 2012, 491(7425): 554-559. [PubMed: 23135404]

33. Dehner M, Hadjihannas M, Weiske J, Huber O, Behrens J. Wnt signaling inhibits Forkhead box O3a-induced transcription and apoptosis through up-regulation of serum- and glucocorticoidinducible kinase 1. J Biol Chem 2008, 283(28): 19201-19210. [PubMed: 18487207]

34. Wang R, Ferraris JD, Izumi Y, Dmitrieva N, Ramkissoon K, Wang G, et al. Global discovery of high-NaCl-induced changes of protein phosphorylation. Am J Physiol Cell Physiol 2014, 307(5): C442-454. [PubMed: 24965592]

35. Irarrazabal CE, Burg MB, Ward SG, Ferraris JD. Phosphatidylinositol 3-kinase mediates activation of ATM by high $\mathrm{NaCl}$ and by ionizing radiation: Role in osmoprotective transcriptional regulation. Proc Natl Acad Sci U S A 2006, 103(23): 8882-8887. [PubMed: 16728507] 
36. Fang D, Hawke D, Zheng Y, Xia Y, Meisenhelder J, Nika H, et al. Phosphorylation of beta-catenin by AKT promotes beta-catenin transcriptional activity. J Biol Chem 2007, 282(15): 11221-11229. [PubMed: 17287208]

37. Lund RJ, Loytomaki M, Naumanen T, Dixon C, Chen Z, Ahlfors H, et al. Genome-wide identification of novel genes involved in early Th1 and Th2 cell differentiation. J Immunol 2007, 178(6): 3648-3660. [PubMed: 17339462]

38. Boniface K, Bak-Jensen KS, Li Y, Blumenschein WM, McGeachy MJ, McClanahan TK, et al. Prostaglandin E2 regulates Th17 cell differentiation and function through cyclic AMP and EP2/EP4 receptor signaling. J Exp Med 2009, 206(3): 535-548. [PubMed: 19273625]

39. Kofler DM, Marson A, Dominguez-Villar M, Xiao S, Kuchroo VK, Hafler DA. Decreased RORCdependent silencing of prostaglandin receptor EP2 induces autoimmune Th17 cells. J Clin Invest 2014, 124(6): 2513-2522. [PubMed: 24812667]

40. Li X, Murray F, Koide N, Goldstone J, Dann SM, Chen J, et al. Divergent requirement for Galphas and cAMP in the differentiation and inflammatory profile of distinct mouse Th subsets. J Clin Invest 2012, 122(3): 963-973. [PubMed: 22326954]

41. Sreeramkumar V, Fresno M, Cuesta N. Prostaglandin E2 and T cells: friends or foes? Immunol Cell Biol 2012, 90(6): 579-586. [PubMed: 21946663]

42. Yao C, Hirata T, Soontrapa K, Ma X, Takemori H, Narumiya S. Prostaglandin E(2) promotes Th1 differentiation via synergistic amplification of IL-12 signalling by cAMP and PI3-kinase. Nat Commun 2013, 4: 1685. [PubMed: 23575689]

43. Shin H, Kwack MH, Shin SH, Oh JW, Kang BM, Kim AA, et al. Identification of transcriptional targets of Wnt/beta-catenin signaling in dermal papilla cells of human scalp hair follicles: EP2 is a novel transcriptional target of Wnt3a. J Dermatol Sci 2010, 58(2): 91-96. [PubMed: 20347274]

44. Castellone MD, Teramoto H, Williams BO, Druey KM, Gutkind JS. Prostaglandin E2 promotes colon cancer cell growth through a Gs-axin-beta-catenin signaling axis. Science 2005, 310(5753): 1504-1510. [PubMed: 16293724]

45. Ding Y, Shen S, Lino AC, Curotto de Lafaille MA, Lafaille JJ. Beta-catenin stabilization extends regulatory T cell survival and induces anergy in nonregulatory T cells. Nat Med 2008, 14(2): 162169. [PubMed: 18246080]

46. van Loosdregt J, Fleskens V, Tiemessen MM, Mokry M, van Boxtel R, Meerding J, et al. Canonical Wnt signaling negatively modulates regulatory T cell function. Immunity 2013, 39(2): 298-310. [PubMed: 23954131]

47. Pappalardo JL, Hafler DA. The Human Functional Genomics Project: Understanding Generation of Diversity. Cell 2016, 167(4): 894-896. [PubMed: 27814519]

48. Wilck N, Matus MG, Kearney SM, Olesen SW, Forslund K, Bartolomaeus H, et al. Salt-responsive gut commensal modulates TH17 axis and disease. Nature 2017.

49. Mahic M, Yaqub S, Johansson CC, Tasken K, Aandahl EM. FOXP3+CD4+CD25+ adaptive regulatory $\mathrm{T}$ cells express cyclooxygenase- 2 and suppress effector T cells by a prostaglandin E2dependent mechanism. J Immunol 2006, 177(1): 246-254. [PubMed: 16785520]

50. Kihara Y, Matsushita T, Kita Y, Uematsu S, Akira S, Kira J, et al. Targeted lipidomics reveals mPGES-1-PGE2 as a therapeutic target for multiple sclerosis. Proc Natl Acad Sci U S A 2009, 106(51): 21807-21812. [PubMed: 19995978] 


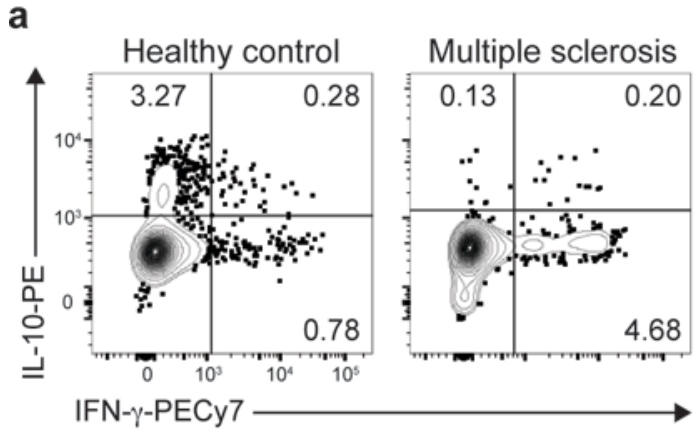

b
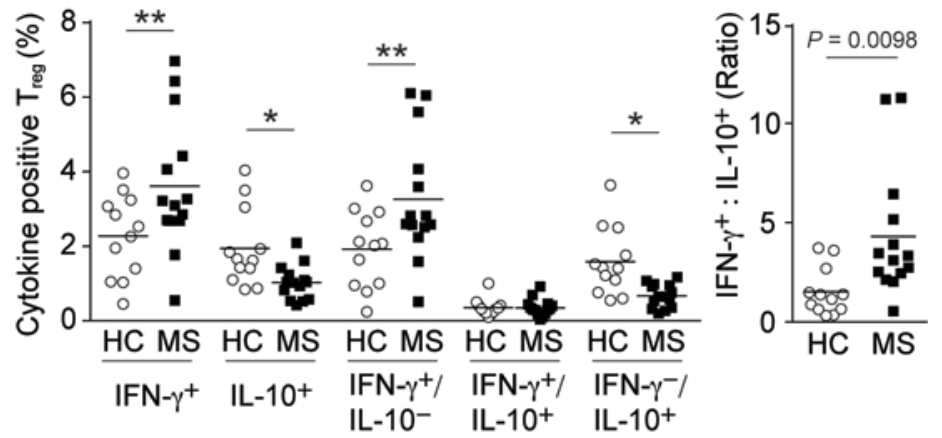

C
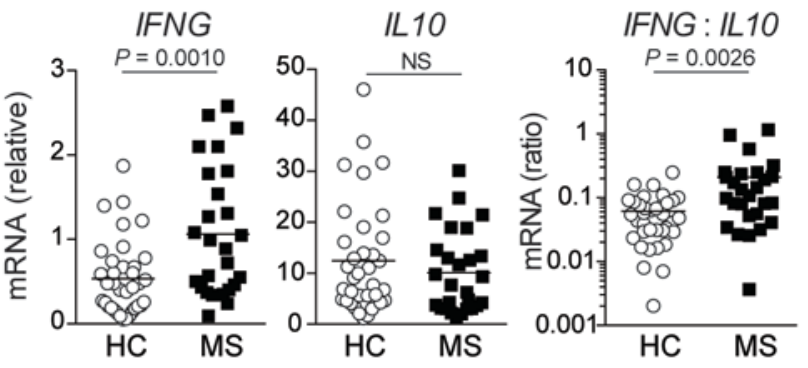

d

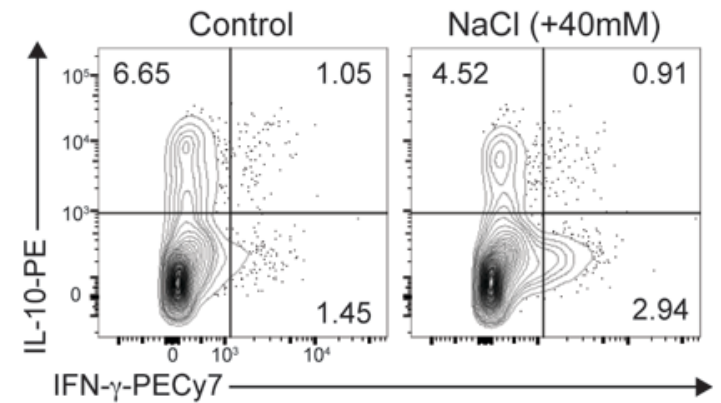

e

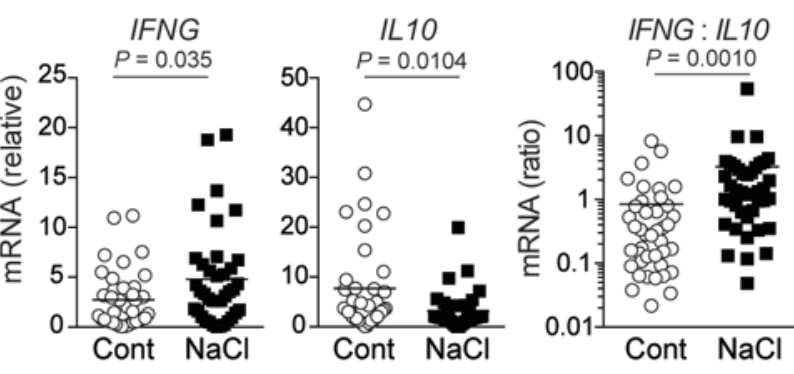

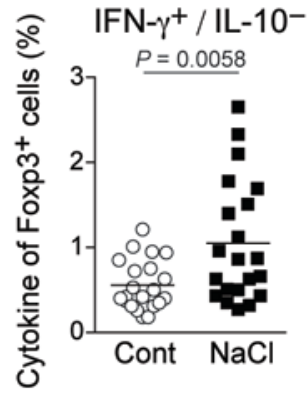

IFN- $\gamma^{-} /$IL-10+

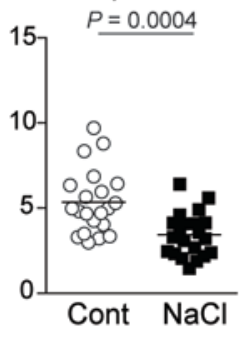

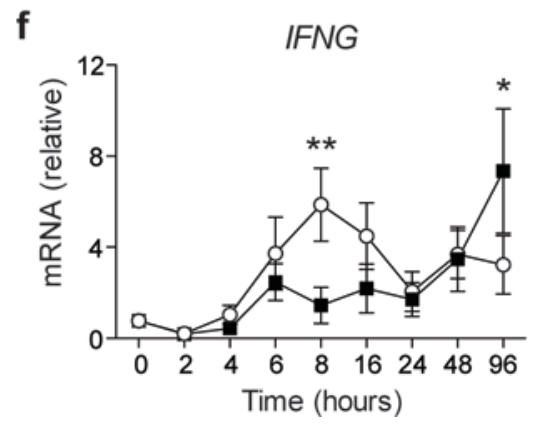

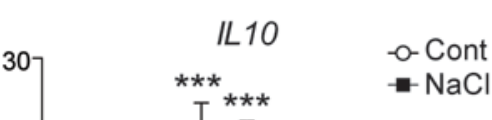

Figure 1. IFN- $\gamma$ :IL-10 balance of human $\mathrm{T}_{\text {reg }}$ cells in MS and high salt treatment.

(a) Representative flow cytometric analysis of ex vivo human $\mathrm{T}_{\text {reg }}$ cells

(CD4+CD25hiCD127lo-negCD45RO+) isolated from healthy donor and MS patient. FACS isolated $\mathrm{T}_{\text {reg }}$ cells were stimulated with PMA plus iomomycin for $4 \mathrm{~h}$ followed by intracellular staining for IFN- $\gamma$ and IL-10. Data are representative of twelve experiments. (b) IFN- $\gamma$ and IL-10 cytokine profiles of ex vivo human $\mathrm{T}_{\text {reg }}$ cells. Percentage of IFN- $\gamma$ and/or IL-10 producing $\mathrm{T}_{\text {reg }}$ cells was shown (left). Ratio between IFN- $\gamma$ positive and IL-10 positive $\mathrm{T}_{\text {reg }}$ cells was plotted (right). (HC; $\mathrm{n}=12, \mathrm{MS} ; \mathrm{n}=14$ subjects) $* P<0.05, * * P<0.01$ 
(two-way ANOVA with Sidak's multiple comparisons test (left), two-sided Student's $t$-test (right)). (c) IFNG and ILIO gene expression was determined on ex vivo $\mathrm{T}_{\text {reg }}$ cells by qPCR. Ratio between $I F N G$ and $I L 10$ expression was shown at the right (HC; n=36, MS; $\mathrm{n}=27$ subjects). $P$ values were calculated by two-sided Student's $t$-test. (d) Representative flow cytometric analysis of IFN- $\gamma$ and IL-10 production in human $\mathrm{T}_{\text {reg }}$ cells stimulated with antiCD3 and anti-CD28 in the normal media (Control) or media supplemented with additional $40 \mathrm{mM} \mathrm{NaCl}(\mathrm{NaCl})$ for $96 \mathrm{~h}$. Data are representative of eight experiments. Percentage of IFN- $\gamma$ and/or IL-10 producing $\mathrm{T}_{\text {reg }}$ cells was shown at the bottom (n=21 subjects). $P$ values were calculated by two-sided Student's $t$-test. (e) $I F N G$ and $I L 10$ mRNA expression was assessed at $96 \mathrm{~h}$ following stimulation as in (d) ( $\mathrm{n}=41$ subjects). Ratio between IFNG and IL10 expression was plotted (right). Each symbol represents an individual subject. $P$ values were calculated by two-sided Student's $t$-test. (f) mRNA expression kinetics of $I F N G$ and IL10 from nine different time points were plotted ( $\mathrm{n}=6$ subjects). ${ }^{*} P<0.05, * * P<0.01$, $* * * P<0.001$ (two-way ANOVA with Sidak's multiple comparisons test). Data were represented as mean (b-e), or mean $+/-$ SEM (e). 
a

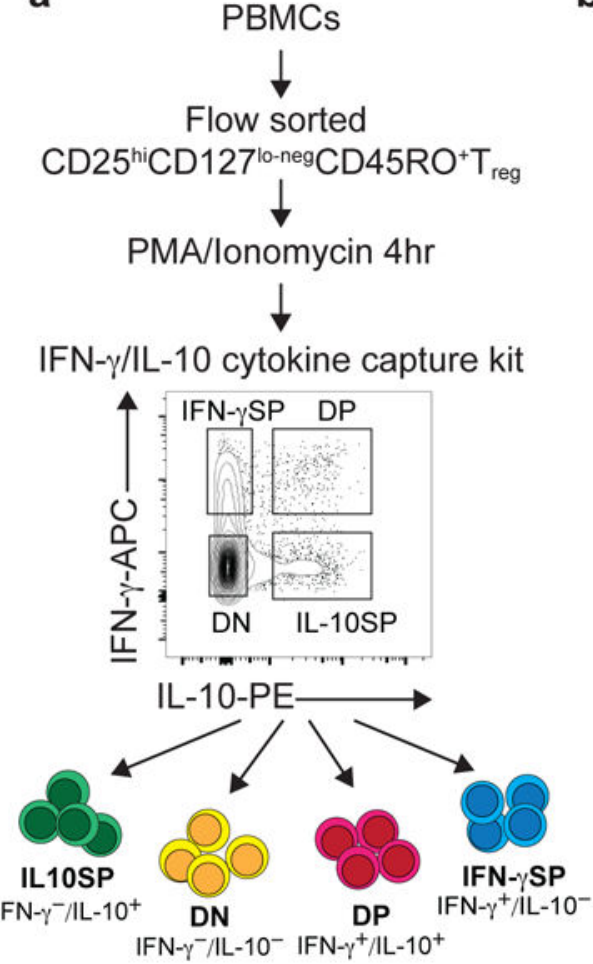

b

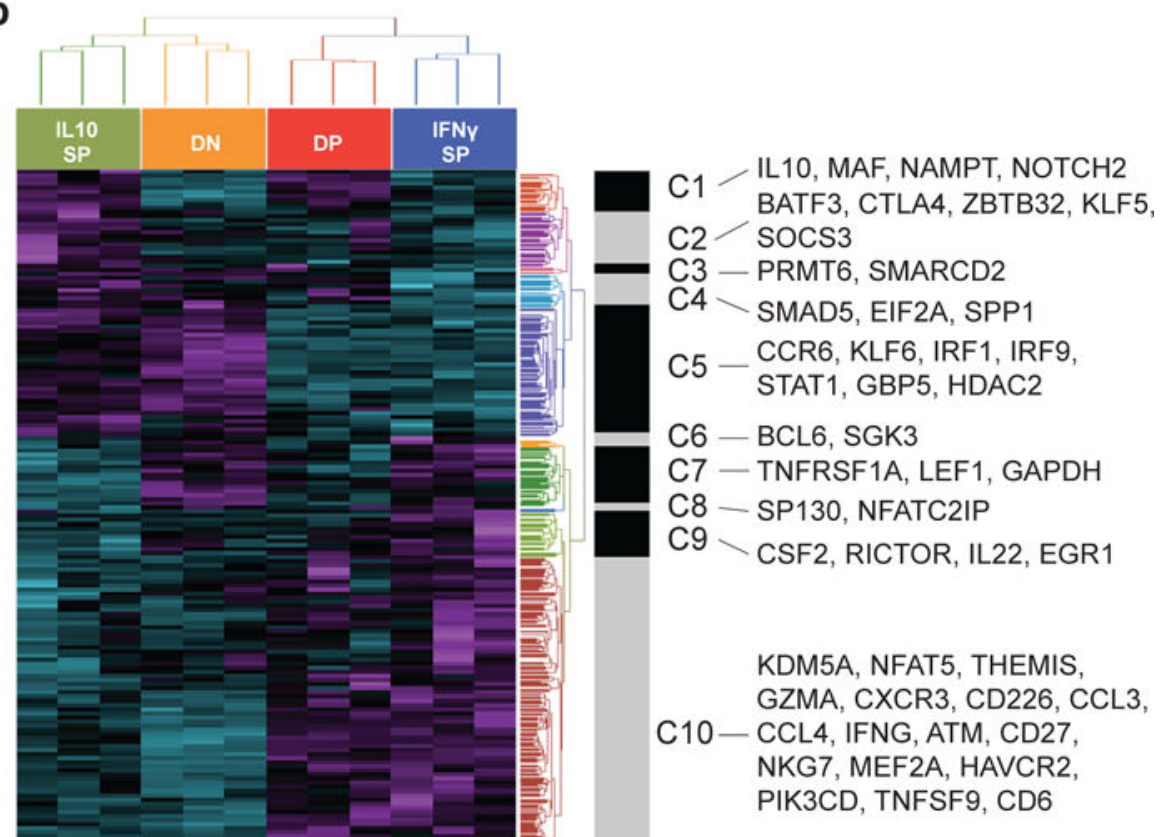

C

IFN- $\gamma$ SP vs. DN

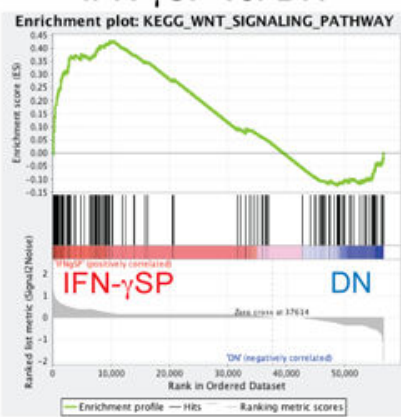

NES $=1.942$

FDR $=0.00$
IFN- $\gamma$ SP vs. IL10SP
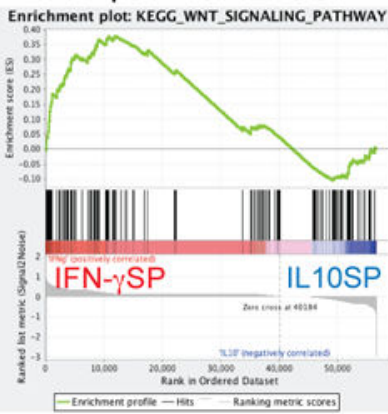

NES $=1.751$

$\mathrm{FDR}=0.006$
IL10SP vs. DN

Enrichment plot: KEGG_WNT_SIGNALING_PATHWAY

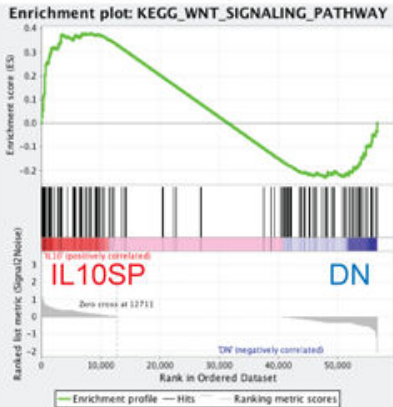

NES $=1.11$

FDR $=0.38$
DP vs. DN

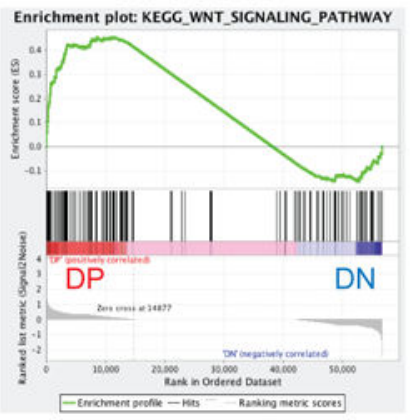

NES $=1.300$

$\mathrm{FDR}=0.024$

Figure 2. Transcriptional profiling of IFN- $\gamma$ and IL-10 producing human $T_{\text {reg }}$ subsets.

(a) Experimental workflow for RNA-seq with IFN- $\gamma$ and/or IL10 producing $T_{\text {reg }}$ subpopulations. (b) Heatmap of 672 differentially expressed genes between IFN- $\gamma$ SP and IL10SP. 10 clusters are identified and representative genes for each cluster are shown. (c) GSEA enrichment plots of KEGG Wnt signaling pathway between INF- $\gamma$ SP vs. DN, INF$\gamma$ SP vs. IL10SP, IL10SP vs. DN, and DP vs. DN. Results were calculated from three subjects performed in the same batch. Normalized enrichment score (NES) and false discovery rate (FDR) were represented at the bottom of each plot. 

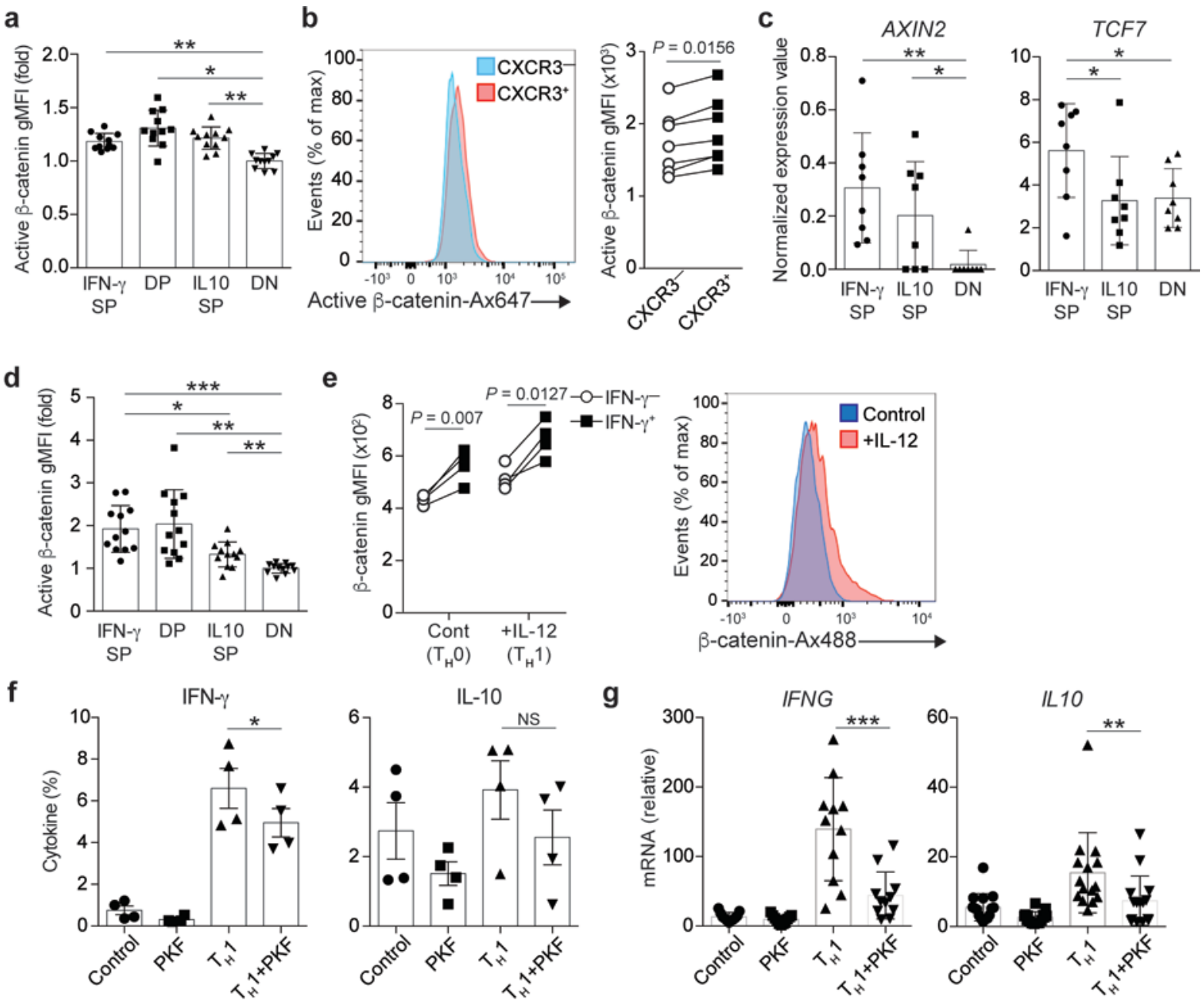

\section{g}
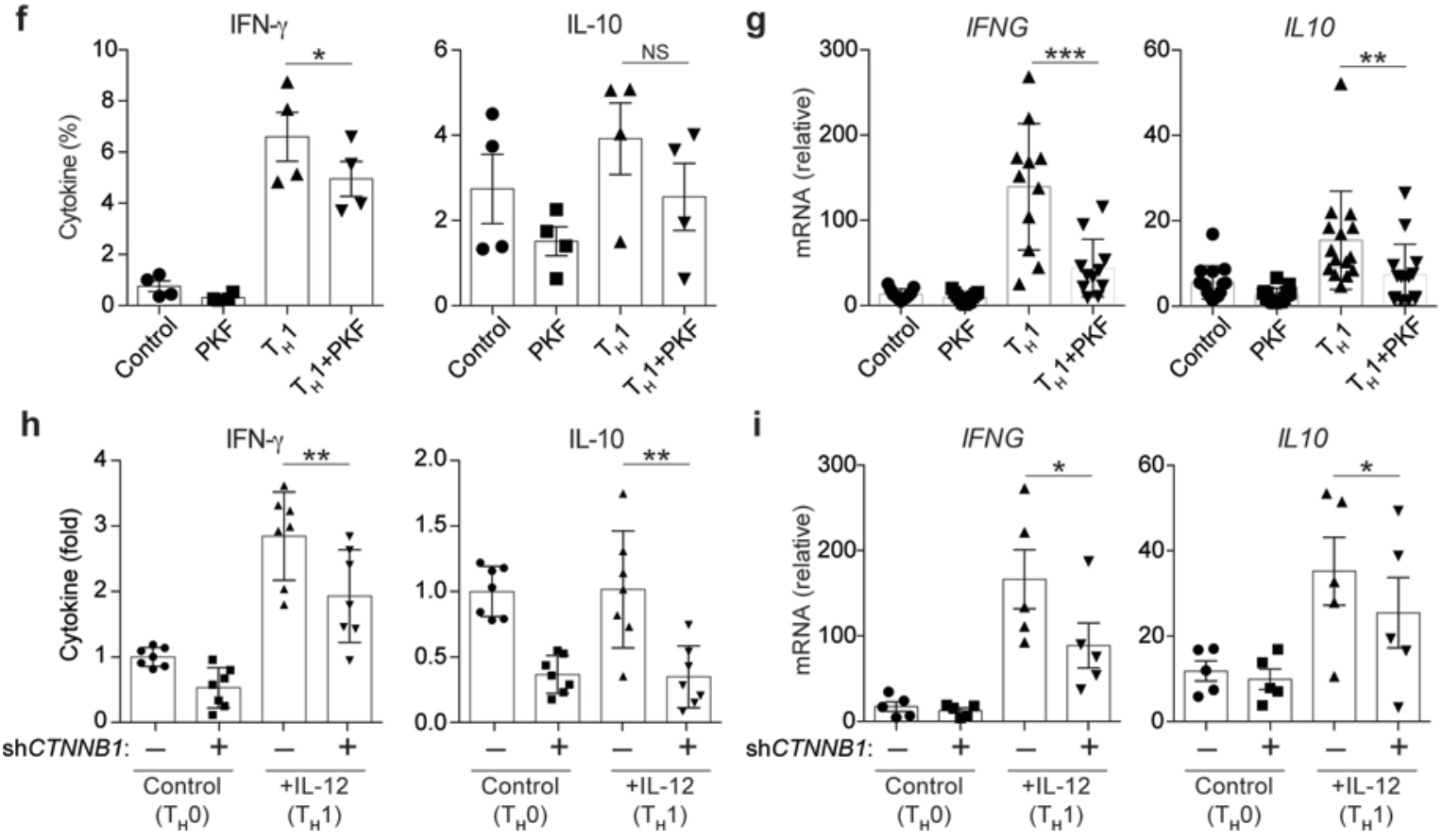

i
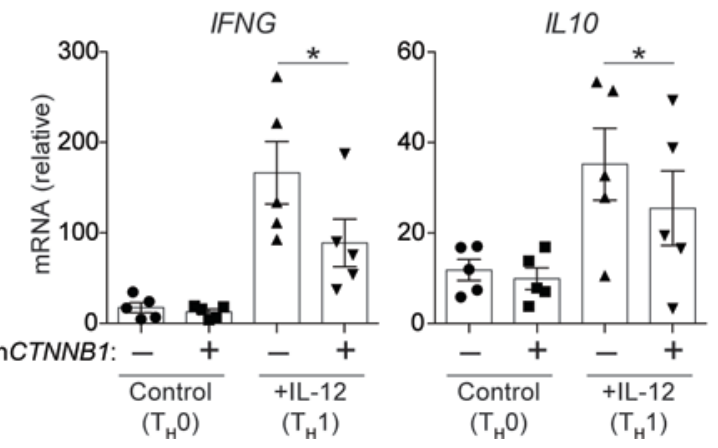

Figure 3. $\beta$-catenin is stabilized in the IFN- $\boldsymbol{\gamma}$ secreting $\mathbf{T}_{\text {reg }}$ subpopulation.

(a) Relative expression level of Active $\beta$-catenin on ex vivo $T_{\text {reg }}$ subpopulations analyzed by flow cytometry ( $\mathrm{n}=11$ subjects). Fold change in gMFI over DN were depicted. $* P<0.05$, $* * P<0.01$ (one-way ANOVA with Tukey's multiple comparisons test). gMFI, geometric mean fluorescence intensity. (b) Expression level of Active $\beta$-catenin between CXCR3- and CXCR3+ ex vivo $\mathrm{T}_{\text {reg }}$ cells from healthy controls. Representative histogram (left) and summary of results (n=7 subjects) (right). $P$ values were calculated by two-sided Student's $t$ test. (c) Gene expression of Wnt- $\beta$-catenin signaling target genes ( AXIN2 and TCF7) 
assessed by RNA-seq ( $\mathrm{n}=8$ subjects). $* P<0.05, * * P<0.01$ (one-way ANOVA with Tukey's multiple comparisons test). (d) Relative expression level of Active $\beta$-catenin on $\mathrm{T}_{\text {reg }}$ cells stimulated with anti-CD3 and anti-CD28 for 4 days, followed by $4 \mathrm{~h}$ PMA plus iomomycin stimulation and intracellular cytokine staining for IFN- $\gamma$ and IL-10 ( $\mathrm{n}=12$ subjects). Fold change in gMFI over DN were depicted. $* P<0.05, * * P<0.01, * * * P<0.001$ (one-way ANOVA with Tukey's multiple comparisons test). (e) Expression level of $\beta$-catenin on $T_{\text {reg }}$ cells stimulated with anti-CD3 and anti-CD28 in the presence $\left(\mathrm{T}_{\mathrm{H}} 1\right)$ or absence $\left(\mathrm{T}_{\mathrm{H}} 0\right)$ of IL-1 2 for 4 days. $\beta$-catenin level on IFN- $\gamma$ positive/negative $T_{\text {reg }}$ populations was determined after $4 \mathrm{~h}$ PMA plus iomomycin stimulation (left) ( $\mathrm{n}=4$ subjects). Representative histogram for $\beta$-catenin expression was shown (right). $P$ values were calculated by two-sided Student's $t$-test. (f, g) Frequency of IFN- $\gamma$ and IL-10 positive cell number (f) and gene expression of IFNG and $I L 10$ by qPCR (g). $\mathrm{T}_{\text {reg }}$ cells were stimulated with anti-CD3 and anti-CD28 in the presence of Wnt/ $\beta$-catenin signaling inhibitor PKF115-584 (PKF), IL-12 $\left(\mathrm{T}_{\mathrm{H}} 1\right)$, or IL-12 and PKF115-584 $\left(\mathrm{T}_{\mathrm{H}} 1+\mathrm{PKF}\right)(\mathrm{n}=4$ subjects $) * P<0.05, * * P<0.01$, $* * * P<0.001$ (one-way ANOVA with Tukey's multiple comparisons test). (h, i) Relative frequency of IFN- $\gamma$ and IL-10 positive cell number (fold of scramble shRNA/control condition) (h) and gene expression of IFNG and ILIO by qPCR (i). $\mathrm{T}_{\text {reg }}$ cells were transduced with a scramble shRNA or a $C T N N B 1$ shRNA and cultured in $\mathrm{T}_{\mathrm{H}} 0$ or $\mathrm{T}_{\mathrm{H}} 1$ condition for 5 days $(\mathbf{h} ; \mathrm{n}=7$ subjects, $\mathbf{i} ; \mathrm{n}=5$ subjects). $* P<0.05, * * P<0.01$ (one-way ANOVA with Tukey's multiple comparisons test). Data are representative of two experiments $(\mathbf{e}, \mathbf{f})$ or are from more than three experiments. Data were represented as mean $+/-\mathrm{SD}$. 
a

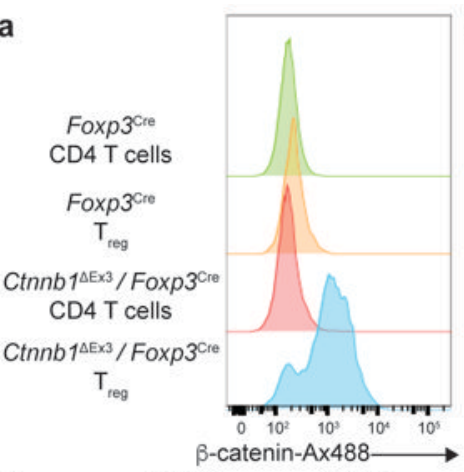

C

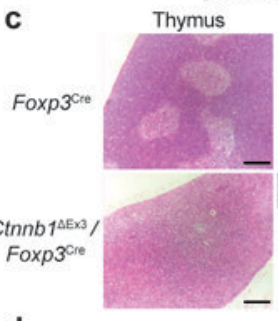

d

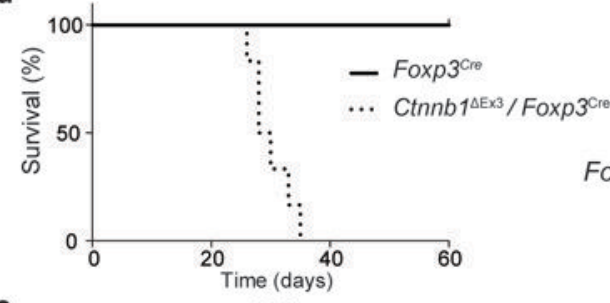

e
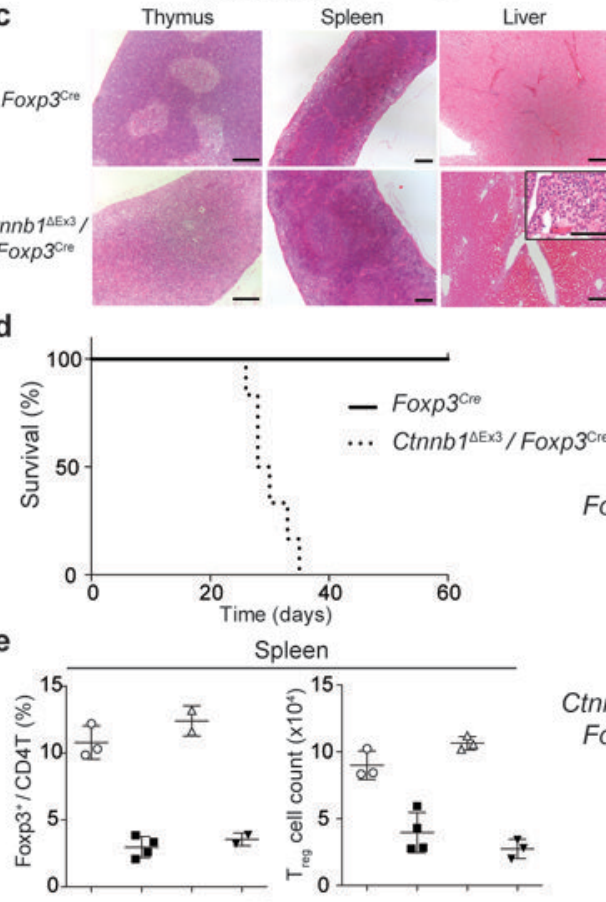

Liver

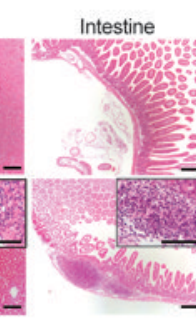

f
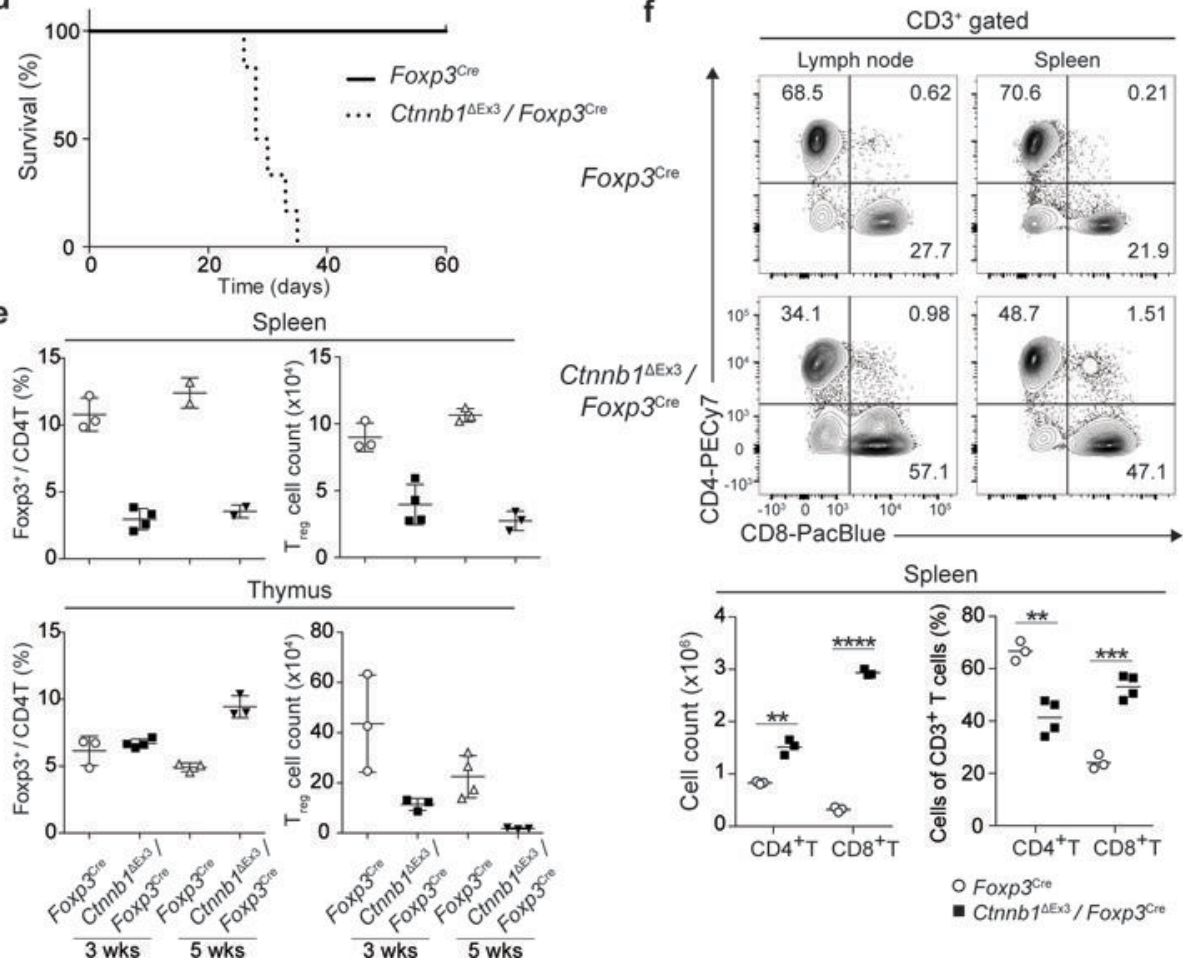

Thymus

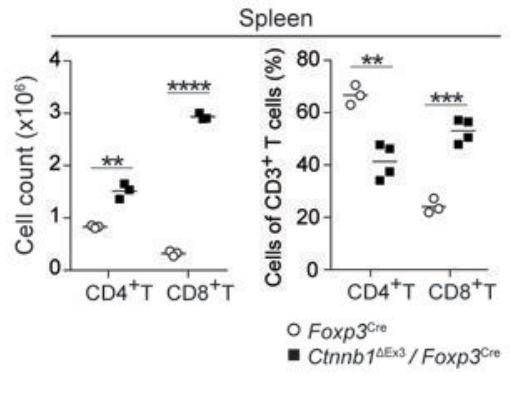

Figure 4. $\mathbf{T}_{\text {reg }}$ specific activation of $\beta$-catenin induces $S c u r f y$-like autoimmunity.

(a) Flow cytometric analysis of $\beta$-catenin on peripheral lymph node $T_{\text {reg }}$ cells and Foxp3CD4+ T cells (CD4T) from Foxp3Cre and Ctnnb1 $1 \mathrm{Ex} 3 /$ Foxp3Cre mice. Data are representative of four experiments. (b) Images of 4-week-old Foxp3Cre mouse and Ctnnb1 1 Ex 3/Foxp3Cre mouse (left). Representative pictures of thymus, peripheral lymph nodes, and spleens isolated from 4 week-old Foxp $3^{C r e}$ or Ctnnb1 1 Ex $3 / F o x p 3 C r e$ mice. (c) Hematoxylin and eosin staining of thymus, spleen, liver, intestine, pancreas, and lung sections from 4 week-old Foxp3Cre and Ctnnb1AEx3/Foxp3Cre mice. Scale bars, $300 \mu \mathrm{m}$ in 
the lower magnification and $150 \mu \mathrm{m}$ in the higher magnification. Results in $(\mathbf{b}, \mathbf{c})$ are representative of six experiments. (d) Survival of Foxp3Cre and Ctnnb1 $\Delta \mathrm{Ex} 3 /$ Foxp3Cre mice. (e) The percentage of $\mathrm{T}_{\text {reg }}$ cells within CD4+ $\mathrm{T}$ cells and the cell numbers of $\mathrm{T}_{\text {reg }}$ cells in spleen (top) and thymus (bottom) from Foxp3Cre and Ctnnb1 $1 \Delta \mathrm{Ex} 3 /$ Foxp3Cre mice at 3 weeks ( $3 \mathrm{wks})$ and 5 week old ( $5 \mathrm{wks})$ of age $(\mathrm{n}=2-4$ mice). (f) Flow cytometric analysis of CD4+ and CD8+ T cells in peripheral lymph nodes and spleens from Foxp3Cre and Ctnnb1 $1 \mathrm{Ex} 3 /$ Foxp3Cre mice at the age of 3 weeks. Cell count and percentages of CD4+ and $\mathrm{CD} 8+\mathrm{T}$ cells among CD3+ $\mathrm{T}$ cells from the spleens were shown at the bottom $(\mathrm{n}=3-4$ mice). $* * P<0.01 * * * P<0.001, * * * * P<0.0001$ (two-way ANOVA with Sidak's multiple comparisons test). Data were represented as mean +/- SD. Data are representative of three experiments. 
a

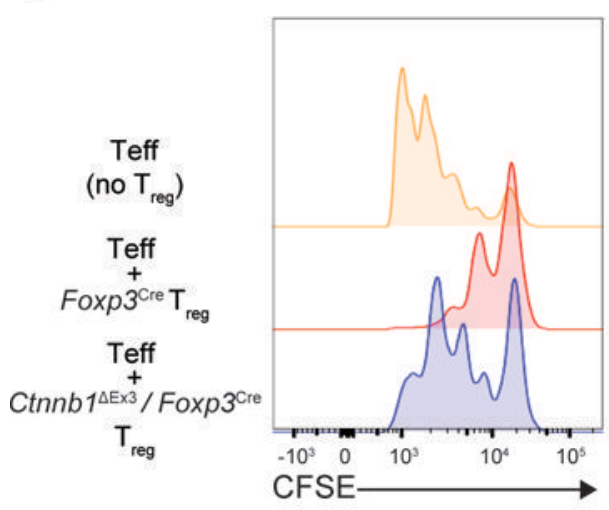

b

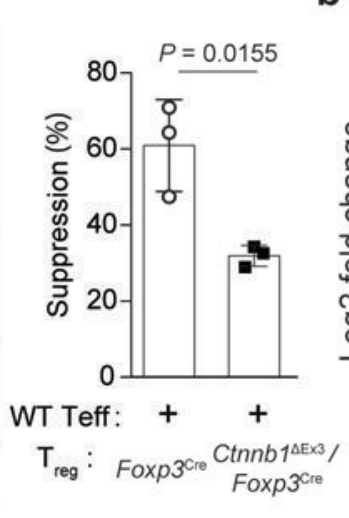

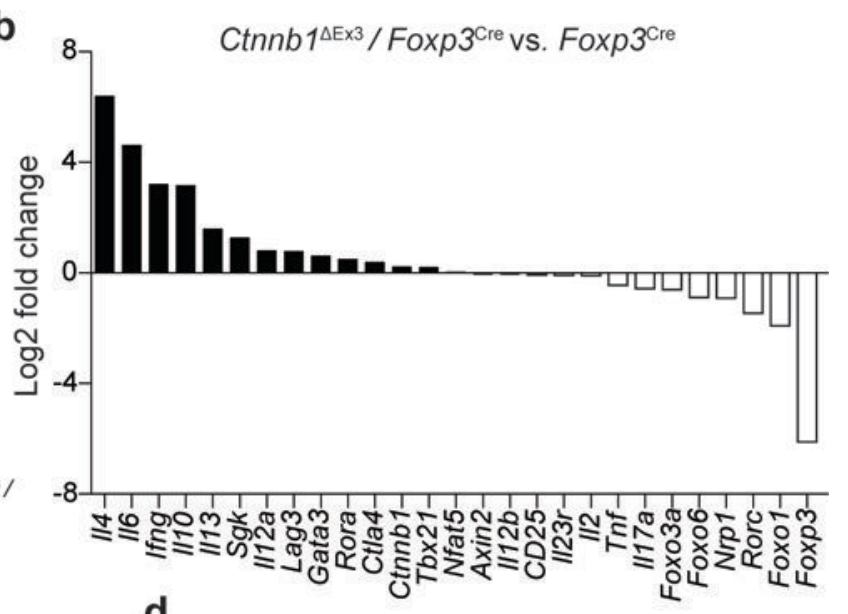

d
C

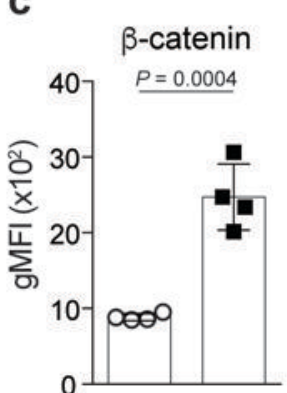

Foxp3

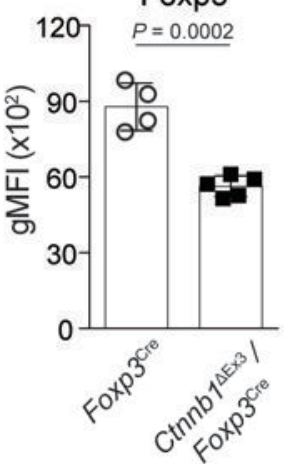

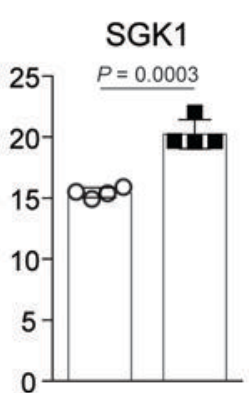

Helios

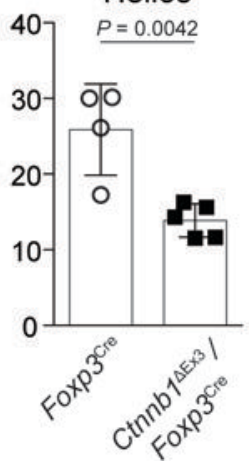

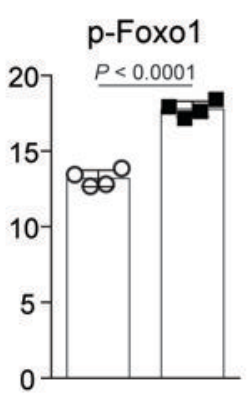

ROR $\gamma \mathrm{t}$

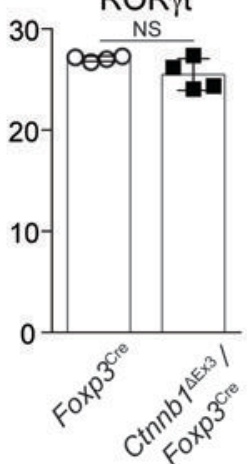

$P<0.0001$

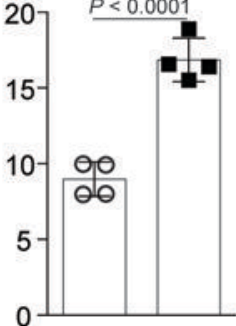

Proximity ligation assay ( $\beta$-catenin/Foxo1)
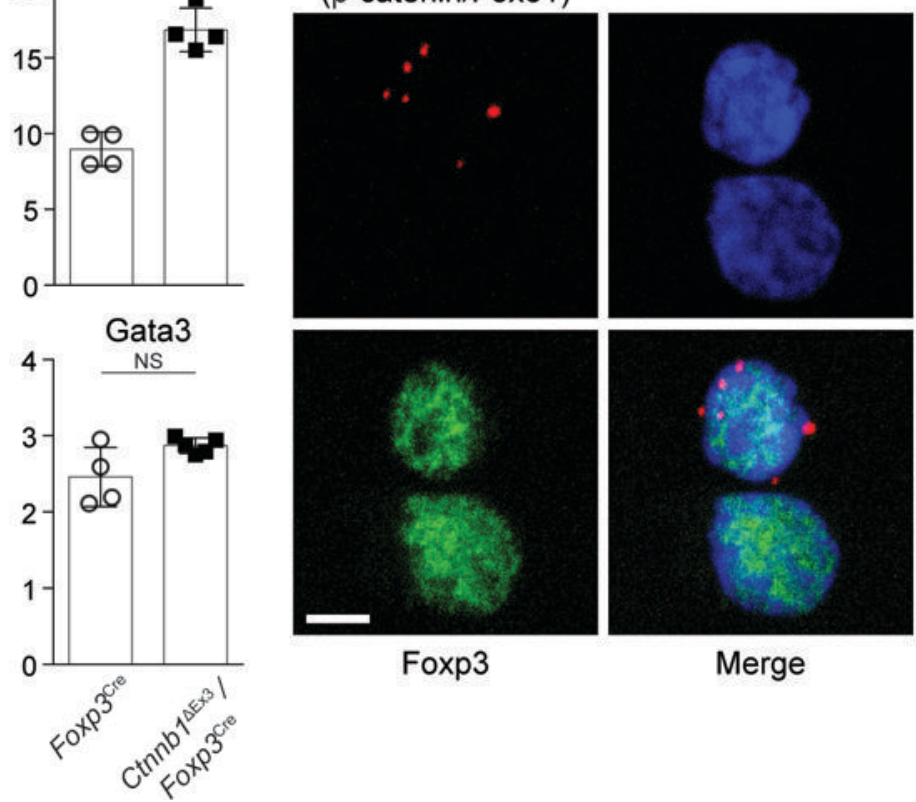

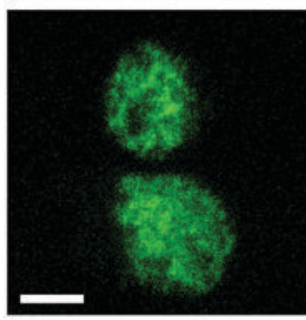

Foxp3

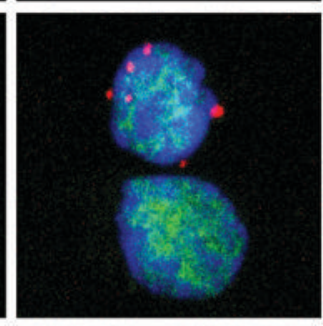

Merge

Figure 5. $\beta$-catenin stabilized $T_{\text {reg }}$ cells represent dysfunctional phenotype with phosphorylation of Foxo1.

(a) Representative histogram of CFSE dilution for $\mathrm{T}_{\text {reg }}$ suppression assay. Yellow; Foxp3 $3^{C r e}$ Teff only, Blue; Foxp3Cre T reg cells and Foxp3Cre Teff at 1:1 ratio, Red; Ctnnb1 Ex 3/ Foxp3Cre $\mathrm{T}_{\text {reg }}$ cells and Foxp3Cre Teff at 1:1 ratio (left). Bar graph shows percentage of suppression (right) (n=3). $P$ values were calculated by two-sided Student's $t$-test. (b) Gene expression profile of Foxp3Cre and Ctnnb1 $\mathrm{Ex} 3 /$ Foxp3Cre $\mathrm{T}_{\text {reg }}$ cells by microarray analysis. (c) Flow cytometric analysis on peripheral lymph node $\mathrm{T}_{\text {reg }}$ cells from Foxp3Cre and Ctnnb1 $\Delta \mathrm{Ex} 3 /$ Foxp3Cre mice. Quantification of gMFI for indicated molecules was shown (Foxp3Cre; n=4 mice, Ctnnb1 Ex 3/Foxp3Cre; $\mathrm{n}=4$ or 5 mice). $P$ values were calculated by two-sided Student's $t$-test. Data were represented as mean and mean $+/-\mathrm{SD}$. (d) Representative immunofluorescence images of human $\mathrm{T}_{\text {reg }}$ cells with PLA signal for $\beta$ catenin-Foxo1 interaction (red) and Foxp3 staining (green). Nuclei were stained with DAPI (blue). Scale bar; $5 \mu \mathrm{M}$. Data were representative of three experiments. 

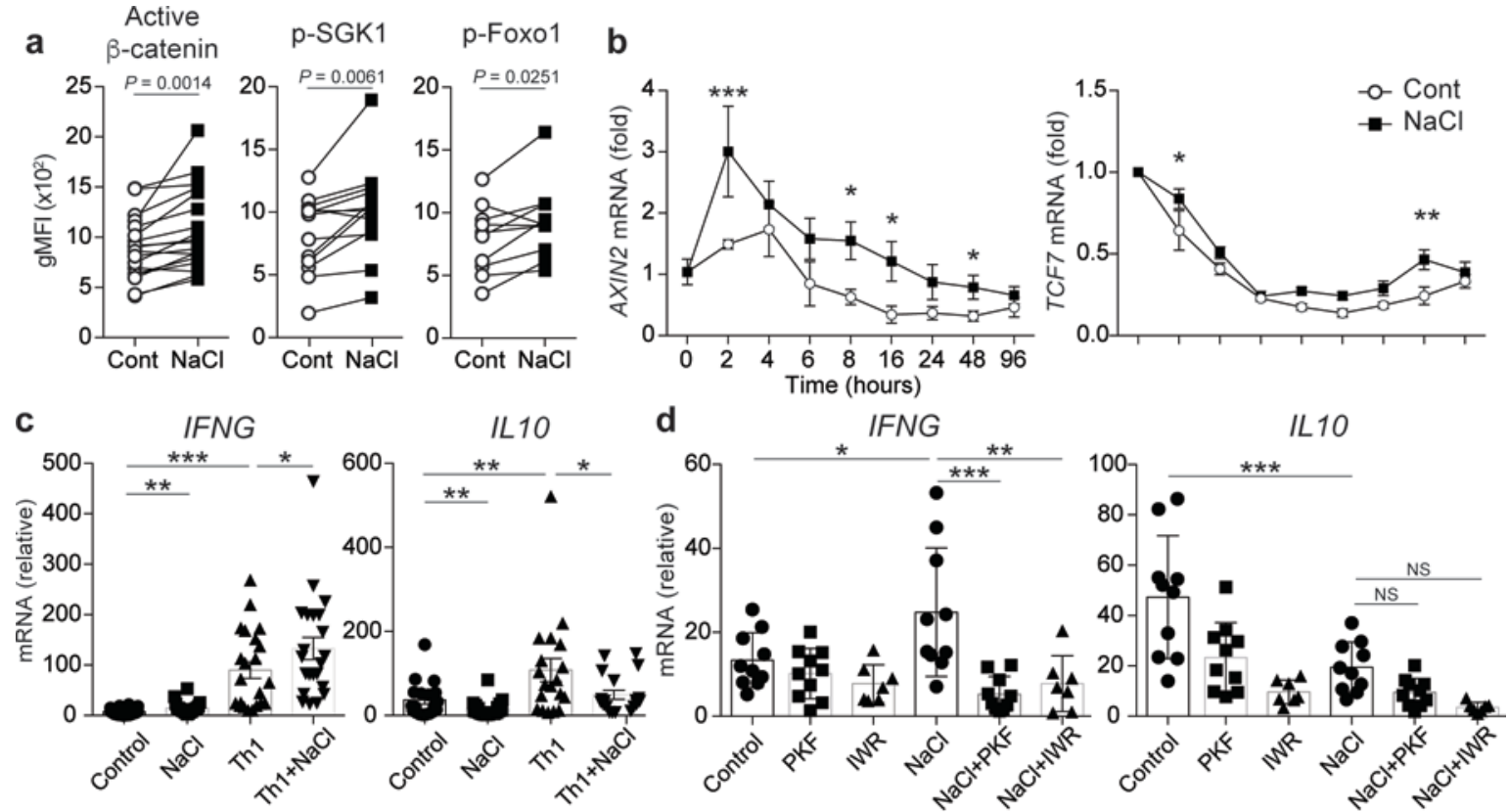

$$
\text { e }
$$

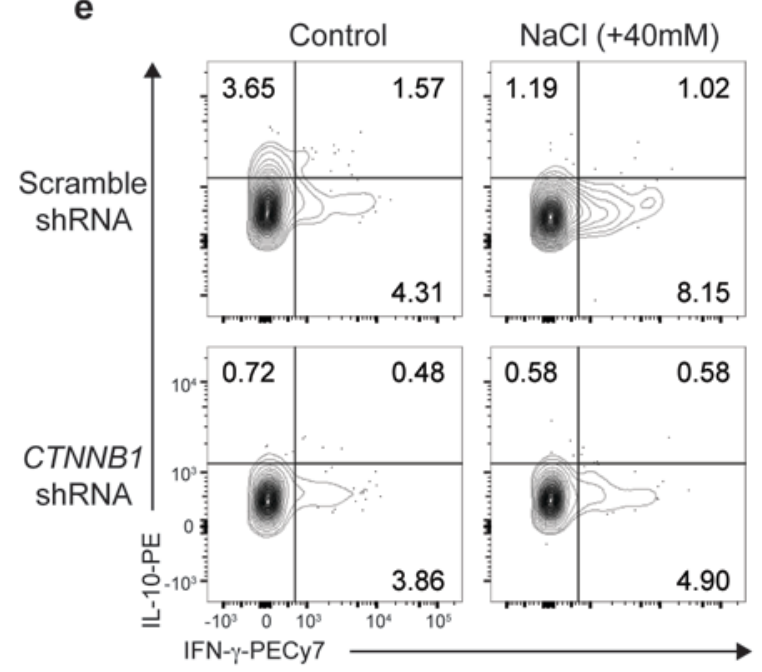

f

IFNG
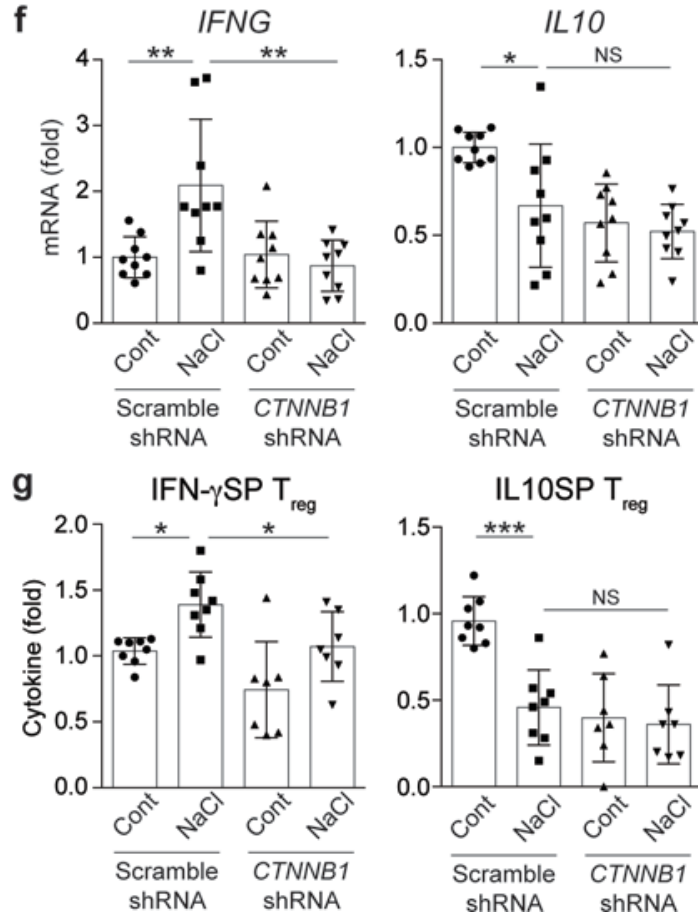

Figure 6. High salt environment induces $\beta$-catenin signal activation and IFN- $\gamma$ :IL-10 cytokine imbalance.

(a) Flow cytometric analysis of Active $\beta$-catenin, p-SGK1 (Thr256), and p-Foxo1 (Ser256) expression in human IFN- $\gamma$-producing $\mathrm{T}_{\text {reg }}$ cells. $\mathrm{T}_{\text {reg }}$ cells were stimulated with anti-CD3 and anti-CD28 in the presence $(\mathrm{NaCl})$ or absence (Control) of additional $40 \mathrm{mM} \mathrm{NaCl}$ for 96 $\mathrm{h}$ followed by $4 \mathrm{~h}$ PMA plus iomomycin stimulation (Active $\beta$-catenin; $\mathrm{n}=18$ subjects, $\mathrm{p}$ SGK1; n=13 subjects, p-Foxo1; n=10 subjects). $P$ values were calculated by two-sided Student's $t$-test. (b) mRNA expression kinetics for Wnt- $\beta$-catenin target genes ( $A X I N 2$ and 
TCF7) from nine time points were plotted and each dots represent the average of four different experiments. $* P<0.05, * * P<0.01, * * * P<0.001$ (two-way ANOVA with Sidak's multiple comparisons test). Data were represented as mean $+/-$ SEM. (c) IFNG mRNA expression in human $\mathrm{T}_{\text {reg }}$ cells cultured in $\mathrm{T}_{\mathrm{H}} 0$ or $\mathrm{T}_{\mathrm{H}} 1$ condition in the presence $(\mathrm{NaCl})$ or absence (Control) of additional $40 \mathrm{mM} \mathrm{NaCl}$ for $96 \mathrm{~h}$ (n=19 subjects). $* P<0.05$, $* * P<0.01$, $* * * P<0.001$ (one-way ANOVA with Tukey's multiple comparisons test). (d) $I F N G$ mRNA expression in human $\mathrm{T}_{\text {reg }}$ cells stimulated in the presence $(\mathrm{NaCl})$ or absence (Control) of additional $40 \mathrm{mM} \mathrm{NaCl}$ with and without Wnt/inhibitor PKF115-584 (PKF) or IWR-1 (IWR) for $96 \mathrm{~h}$ ( $\mathrm{n}=7-10$ subjects). $* P<0.05$ (one-way ANOVA with Tukey's multiple comparisons test). (e) Representative flow cytometric analysis of IFN- $\gamma$ and IL-10 production in human $\mathrm{T}_{\text {reg }}$ cells transduced with a non-targeted shRNA or a CTNNB1 shRNA and cultured in the normal media (Control) or media supplemented with additional $40 \mathrm{mM} \mathrm{NaCl}(\mathrm{NaCl})$ for $96 \mathrm{~h}$. Data are representative of three experiments. (f) IFNG and IL 10 mRNA expression on $\mathrm{T}_{\text {reg }}$ cells, and (g) frequency of IFN- $\gamma$ and IL-1 0 producing $\mathrm{T}_{\text {reg }}$ cells relative to control/scramble shRNA condition were shown. $\mathrm{T}_{\text {reg }}$ cells were treated as in (e) (f; $\mathrm{n}=9$ subjects, $\mathbf{g} ; \mathrm{n}=8$ subjects). $* P<0.05$, $* * P<0.01, * * * P<0.001$ (one-way ANOVA with Tukey's multiple comparisons test). Data were represented as mean +/- SD. 
a

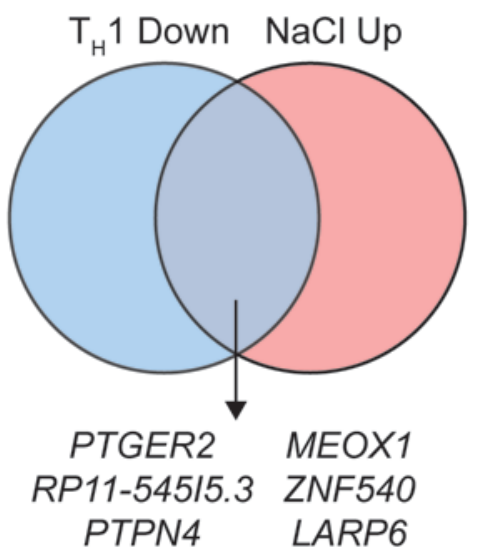

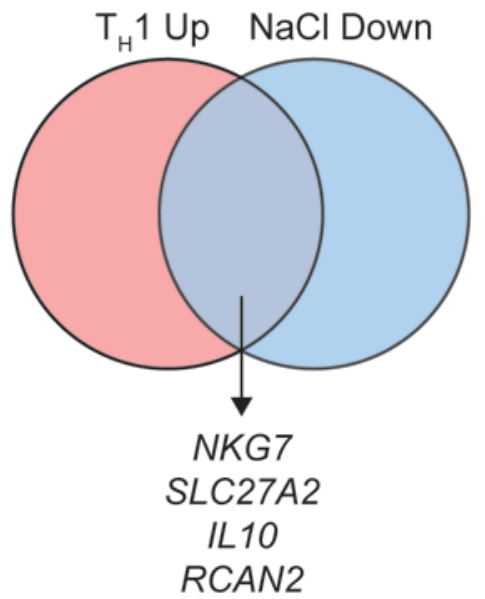

b
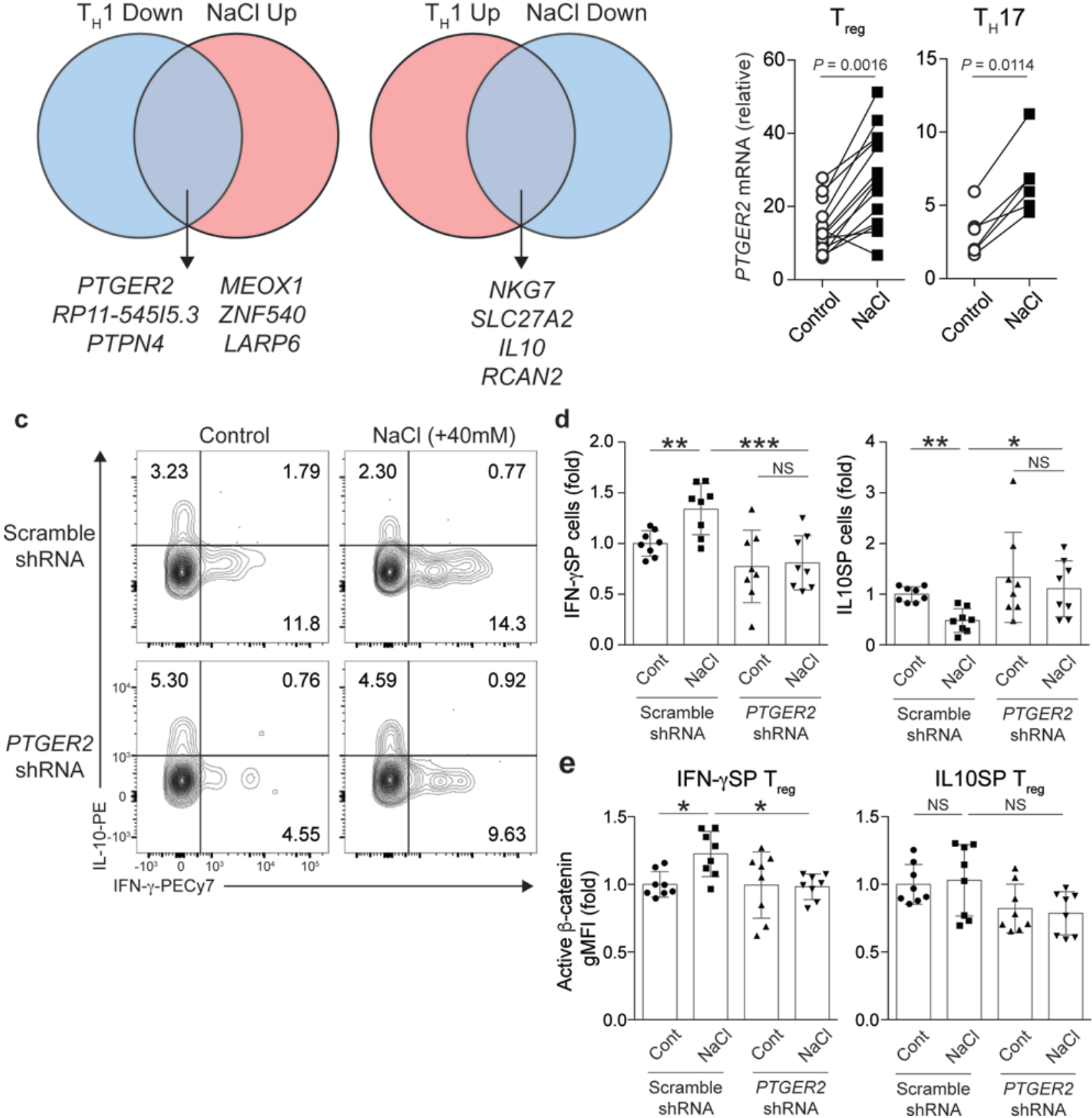

Figure 7. PTGER2 is a unique factor regulating IFN- $\gamma$ and IL-10 in conjunction with $\beta$-catenin under high salt condition.

(a) Venn diagrams showing the overlapped genes between the genes upregulated in $\mathrm{NaCl}$ treatment $(\mathrm{NaCl} \mathrm{Up})$ and downregulated in $\mathrm{T}_{\mathrm{H}} 1$ condition $\left(\mathrm{T}_{\mathrm{H}} 1\right.$ Down) (left), and between the genes downregulated in $\mathrm{NaCl}$ treatment $\left(\mathrm{NaCl}\right.$ Down) and upregulated in $\mathrm{T}_{\mathrm{H}} 1$ condition ( $\mathrm{T}_{\mathrm{H}} 1 \mathrm{Up}$ ) (right). (b) PTGER2 mRNA expression in human $\mathrm{T}_{\text {reg }}$ cells (left) and $\mathrm{T}_{\mathrm{H}} 17$ cells (right). $\mathrm{T}_{\text {reg }}$ cells were stimulated with anti-CD3 and anti-CD28 in the normal media (Control) or media supplemented with additional $40 \mathrm{mM} \mathrm{NaCl}(\mathrm{NaCl})$ for $96 \mathrm{~h}(\mathrm{n}=14$ 
subjects). Naive $\mathrm{CD} 4+\mathrm{T}$ cells were cultured in the normal $\mathrm{T}_{\mathrm{H}} 17$ condition (Control) or $\mathrm{T}_{\mathrm{H}} 17$ condition supplemented with additional $40 \mathrm{mM} \mathrm{NaCl}(\mathrm{NaCl})$ for $72 \mathrm{~h}$ ( $\mathrm{n}=6$ subjects). $P$ values were calculated by two-sided Student's $t$-test. (c) Representative flow cytometric analysis of IFN- $\gamma$ and IL-10 production in human $\mathrm{T}_{\text {reg }}$ cells transduced with a scramble shRNA or a PTGER 2 shRNA and cultured in the normal media (Control) or media supplemented with additional $40 \mathrm{mM} \mathrm{NaCl}(\mathrm{NaCl})$ for $96 \mathrm{~h}$. Data are representative of three experiments. (d) Relative frequency of IFN- $\gamma$ and IL-10 producing $\mathrm{T}_{\text {reg }}$ cells, and (e) relative expression level of Active $\beta$-catenin in $T_{\text {reg }}$ cells were shown. $T_{\text {reg }}$ cells were treated as in (c) (d, $\mathbf{e} ; \mathrm{n}=8$ subjects). $* P<0.05, * * P<0.01, * * * P<0.001$ (one-way ANOVA with Tukey's multiple comparisons test). Data were represented as mean $+/-\mathrm{SD}$. 
a

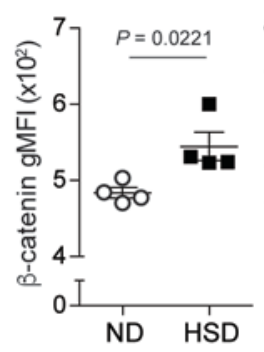

C
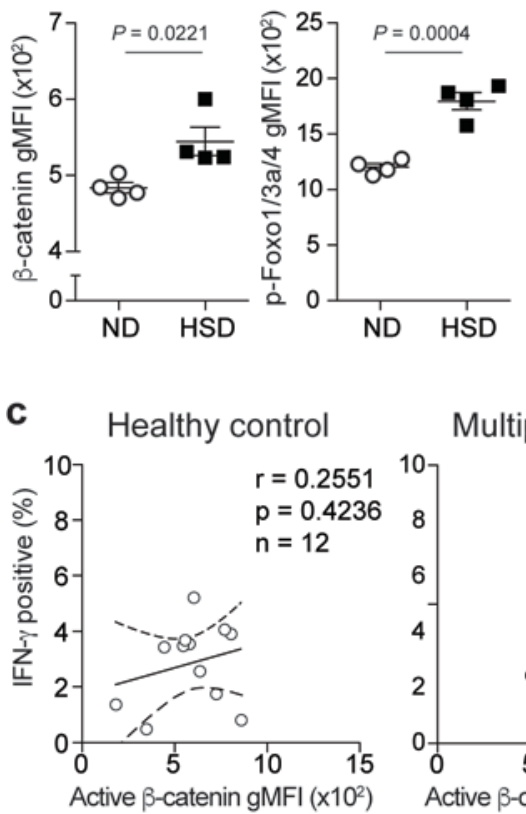

b

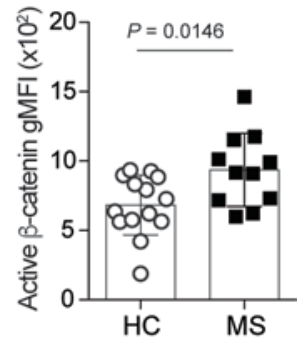

Multiple sclerosis
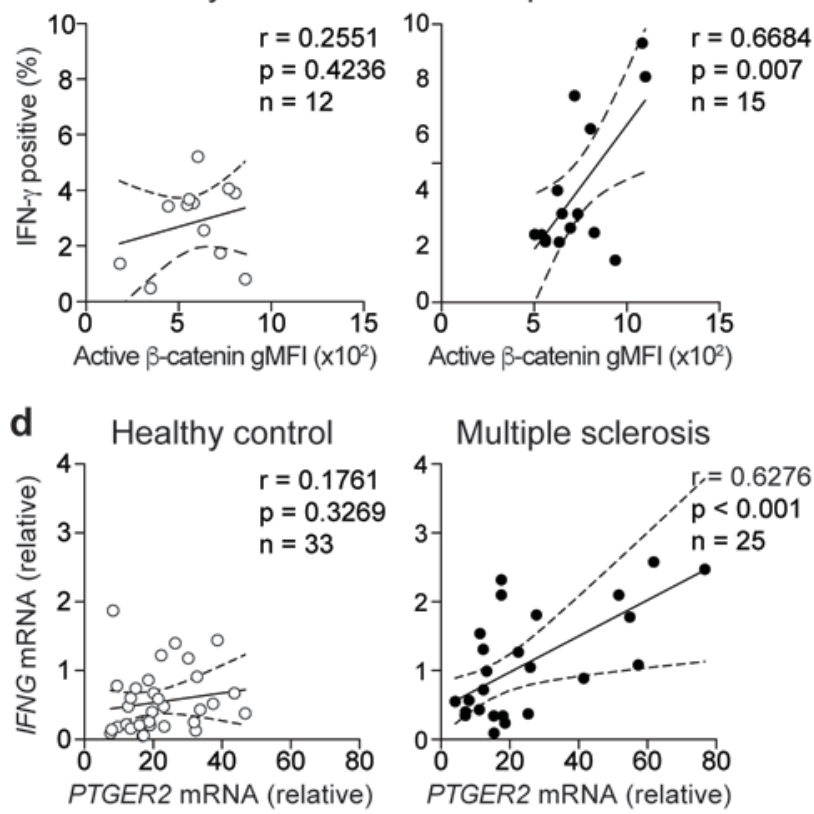

Multiple sclerosis
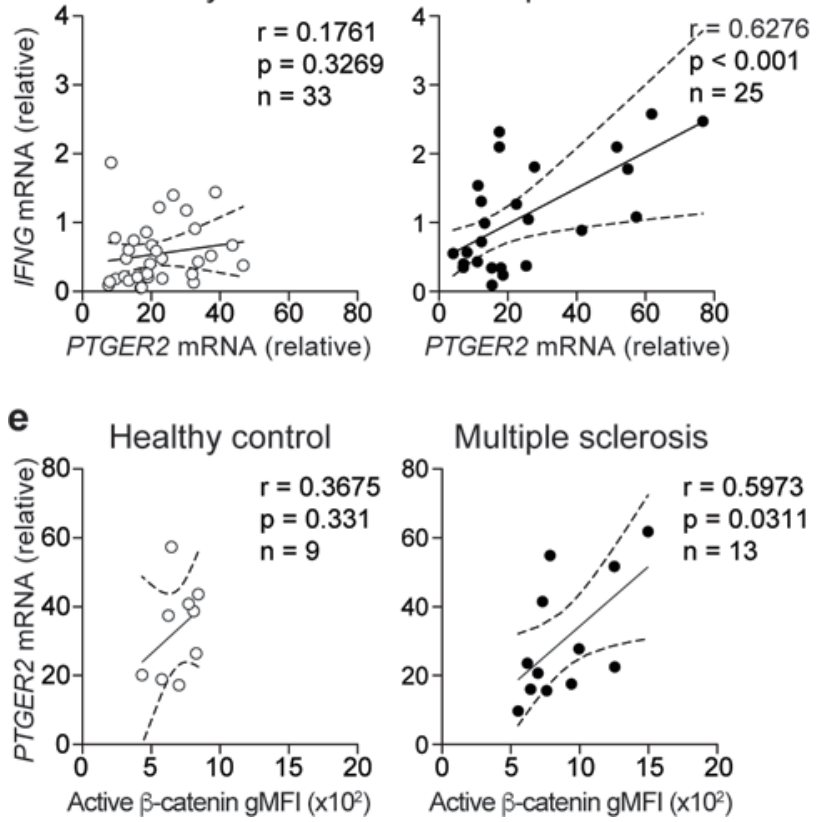

Figure 8. Stabilized $\beta$-catenin associated with IFN- $\gamma$ and PTGER2 expression in $T_{\text {reg }}$ cells from MS patients.

(a) Flow cytometric analysis of $T_{\text {reg }}$ cells from the mesenteric lymph nodes of wild type mice fed a normal diet (ND) or a high-salt diet (HSD) for 3 weeks. Quantification of gMFI for $\beta$-catenin and $\mathrm{p}$-Foxo1/3a/4 were shown (ND; $\mathrm{n}=4, \mathrm{HSD} ; \mathrm{n}=4)$. $P$ values were calculated by two-sided Student's $t$-test. (b) Flow cytometric analysis of ABC level in ex vivo $\mathrm{T}_{\text {reg }} \mathrm{s}$ of healthy controls and MS patients (HC; n=14 subjects, MS; n=11 subjects). $P$ value was calculated by two-sided Student's $t$-test. Data were represented as mean $+/-$ SD. (c-e) 
Correlation plots (c); between the percentage of IFN- $\gamma$-producing $\mathrm{T}_{\text {reg }}$ cells and gMFI of Active $\beta$-catenin, (d); between IFNG and PTGER 2 mRNA expression, (e); between Active $\beta$-catenin level and PTGER 2 mRNA expression level in healthy subjects and MS patients. Linear regression is shown with $95 \%$ confidence interval (dotted lines). Correlation statistics by two-sided Spearman rank correlation test. 